\title{
Franz Kerff
}

\section{,Altar' und ,Person ${ }^{\varsigma_{*}}$}

\section{Logische Divisionsprobleme und kirchliche Rechtswirklich- keit im 11. und 12. Jahrhundert, dargestellt an Beispielen aus der ehemaligen Diözese Tournai}

Die Bischöfe und Archidiakone, die Pröpste, Dekane und Äbte, die Kanoniker und Mönche, die während des 11. und 12. Jahrhunderts an Verträgen über Niederkirchen beteiligt gewesen sind, gehörten dem Kreis der Gebildeten ihrer jeweiligen kirchlichen Institutionen und damit der Elite ihrer Zeit an. Die Rechtsakte, die sie im Interesse ihres Kollegiatkapitels oder ihrer Abtei abgeschlossen haben, sind aus Gründen der Beweissicherung regelmäßig beurkundet worden. Diese Urkunden gestatten nun dem heutigen Betrachter nicht nur einen Einblick in das Rechtsleben und damit einen Überblick über die Einrichtungen und Handlungen in der damaligen Rechtswirklichkeit; diese Urkunden zeigen auch das Vermögen zu begrifflicher Distinktion, dem die Schuldisziplin der Dialektik gewiß zugrundegelegen hat. ${ }^{1}$ Freilich findet sich in den Urkundentexten selbst keine konkrete Beschreibung der Formalbildung, die den am Rechtsgeschäft Beteiligten zuteil geworden war. Genannt sind lediglich die Weihegrade oder die bekleideten Kirchenämter. Jedoch muß die Fähigkeit zur Analyse einer Rechtslage, die Fähigkeit zur

* Die vorliegende Darstellung bietet ein Teilergebnis einer größeren Studie zur Rechts- und Kirchengeschichte der Diözese Tournai während des Hochmittelalters. Ludwig Falkenstein (Aachen) danke ich für zahlreiche, diese Darstellung fördernde Gespräche.

1 Zur Schule des Kathedralkapitels von Tournai, zur Ausbildung der Kathedralkanoniker sowie zum Schulwesen in der Bischofsstadt vgl. Jacques Pycke, Le Chapitre Cathédral Notre-Dame de Tournai de la fin du XIe à la fin du XIIIe siècle. Son organisation, sa vie, ses membres (Université de Louvain - Recueil de travaux d'histoire et de philologie 30, Louvainla-Neuve - Bruxelles 1986) 271-288; im folgenden zitert: Pycke, Chapitre Cathédral. Vgl. auch Thérèse de Hemptinne, Over kannuniken en intellectuelen in de middeleeuwen. Nota's bij recente publicaties aangaande kapittels, prosopografien en dataverwerking, in: Handelingen der Maatschappij voor geschiedenis en oudheidkunde te Gent 41 (1987) 195-199. Zur Konservierung der literarischen Kultur und der Wissenschaften im Gebiet des heutigen Belgien von der Karolingerzeit bis zur Mitte des 11.Jahrhunderts sowie zum anschließenden Wiederaufleben bis zur vollen Entfaltung während des 12. Jahrhunderts vgl. Algemene Geschiedenis der Nederlanden 3 (1982) 328-342; zur Rechtsentwicklung in Flandern, im Hennegau und in Brabant während des Hochmittelalters vgl. ebd. 145-163. 
Formulierung eines entsprechenden Vertrages auf einem schulmäßig organisierten Trivialunterricht beruht haben. ${ }^{2}$

\section{Die Diözese Tournai}

Zunächst sei das Untersuchungsgebiet für die Zeit des 11. und 12.Jahrhunderts betrachtet. Die Diözese Tournai, eine der zwölf Diözesen der Kirchenprovinz Reims, erstreckte sich von der Scarpe im Süden bis nahe an die heutige Westerschelde im Norden; die sogenannten Vier Ambachten mit den Vororten Boekhoute, Assenede, Axel und Hulst südlich der Westerschelde gehörten zum Bistum Utrecht. Die östliche Diözesangrenze bildete die Schelde, die damals gleichzeitig Reichsgrenze war, die westliche Diözesangrenze bildeten die Kanalküste und die Flüsse IJzer und Lys. ${ }^{3}$ Die Diözese Tournai grenzte nördlich an Utrecht, das zur Kirchenprovinz Köln gehörte; die Nachbardiözesen im Westen, Süden und Osten - Thérouanne, Arras und Cambrai - gehörten zur Kirchenprovinz Reims. Wohl seit dem 7.Jahrhundert wurde Tournai in Personalunion mit der Diözese Noyon geleitet; der Bischof von Noyon war gleichzeitig Bischof von Tournai. Dieser Zustand wurde erst 1146 mit der Aufhebung der Personalunion beendet; von diesem Zeitpunkt an übernahm das Kathedralkapitel von Tournai nicht mehr die Wahlentscheidung der Kathedralkanoniker von Noyon, sondern wählte seinen Ordinarius selbst. ${ }^{4}$

In der Diözese waren eine Reihe bedeutender kirchlicher Institutionen gelegen. Hier ist zuerst zu nennen das Kathedralkapitel der Kirche Notre-Dame de Tournai, einer Kirche, die heute zu den eindrucksvollsten Sakralbauten Westeuropas

2 Zu dem Umstand, daß das Scholasteramt an der Kathedralschule von Tournai mehrfach das Sprungbrett für eine spätere Karriere als Leiter einer Abtei oder eines Kollegiatkapitels gewesen ist, vgl. Pycke, Chapitre Cathédral 271-274. Vgl. zur mittelalterlichen Wissensvermittlung und zu deren Organisation zuletzt Johannes Fried $(\mathrm{Hg}$.), Schulen und Studium im sozialen Wandel des hohen und späten Mittelalters (Vorträge und Forschungen 30, Sigmaringen 1986).

3 Vgl. zuletzt Pycke, Chapitre Cathédral 25 mit Abb. 26; Édouard de Moreau, Histoire de l'Église en Belgique. Tome complémentaire I: Circonscriptions ecclésiastiques, chapitres, abbayes, couvents en Belgique avant 1559 (Bruxelles 1948) Kartenbeilagen; Etienne Warichez, La géographie historique des diocèses de Cambrai et de Tournai, in: Collationes diocesis Tornacensis 19 (1923-1924) 59-70, 203-213, 241-250.

${ }^{4}$ Zur Personalunion und zu deren Aufhebung vgl. Pycke, Chapitre Cathédral 25-27; Ludo Milis, Beroering omtrent bisdomssplitsingen in Vlaanderen in de jaren 1112-1113, in: Pascua Mediaevalia. Studies voor Prof. Dr. J. M. De Smet, ed. $R$. Lievens, E. Van Mingroot, W. Verbeke (Mediaevalia Lovanensia I, 10, Leuven 1983) 5-14, ebd. 11-14; Nicolas Huyghebaert, Les abbés de Saint-Bertin et la restauration du diocèse de Tournai, in: Bulletin trimestriel de la Société académique des antiquaires de la Morinie 20 (1966) 417-426, im folgenden zitiert: Huyghebaert, Abbés de Saint-Bertin; Anselme Dimier, Saint Bernard et le rétablissement de l'évêché de Tournai, in: Citeaux in de Nederlanden 4 (Westmalle 1953) 206-217. Zu der heftig umkämpften, erst nach dem siebten Versuch vollzogenen Auflösung der Personalunion zwischen Noyon und Tournai bereitet Verfasser eine ausführliche Darstellung vor. 
zählt; mit dem Bau dieser Kathedrale wurde im 12.Jahrhundert begonnen. ${ }^{5}$ Das Kollegiatkapitel Sint Donatiaan in Brugge hat durch die in seinen Mauern geschehene Ermordung des Grafen Karl des Guten von Flandern 1127 traurige Berühmtheit erlangt. ${ }^{6}$ Das Kollegiatkapitel Saint-Pierre in Lille ist, wie Sint Donatiaan, eine Gründung der Grafen von Flandern gewesen. ${ }^{7}$ Die Benediktinerabteien Sint Baafs und Sint Pieters in Gent sowie Saint-Amand d'Elnon blickten zu Beginn des 11.Jahrhunderts bereits auf eine mehrhundertjährige Geschichte zurück, während Saint-Martin in der Bischofsstadt erst gegen Ende dieses Jahrhunderts gegründet wurde. ${ }^{8}$ Hinter die alten und mächtigen Benediktinerabteien, aber auch hinter die gräflichen Gründungen Sint Donatiaan und Saint-Pierre traten die Regularkanonikerabteien wie Saint-Nicolas-des-Prés bei Tournai, Saint-Calixte in Cysoing und Saint-Christophe in Phalempin an Bedeutung deutlich zurück.'

5 Vgl. Pycke, Chapitre Cathédral 37-38. Vgl. auch Jean Dumoulin-Jacques Pycke, La cathédrale Notre-Dame de Tournai hier et aujourd'hui, Tournai 1985.

6 Vgl. G. Declercq, Wanneer ontstond het Sint Donaaskapittel te Brugge?, in: Handelingen van het Genootschap voor Geschiedenis gesticht onder de benaming, Société d'émulation de Bruges` 122 (1985) 145-157, der die Gründung nicht zu Zeiten des Grafen Balduin V. von Flandern (1035-1067), sondern zwischen 918 und 944 angesetzt wissen will. Zu den Pröpsten von Sint Donatiaan, seit 1089 in Personalunion auch Kanzler der Grafen von Flandern und Leiter der gräflichen Domänenverwaltung, während der Herrschaft der Grafen Dietrich und Philipp vgl. Adriaan Verbulst - Thérèse de Hemptinne, Le chancelier de Flandre sous les comtes de la maison d'Alsace (1128-1191), in: Bulletin de la Commission royale d'Histoire 141 (1975) 267-311. Zu dem tagebuchartigen Bericht über die Ermordung Karls des Guten, meines Erachtens die faszinierendste erzählende Quelle des 12.Jahrhunderts, vgl. die Edition von Henri Pirenne, Histoire du meurtre de Charles le Bon, comte de Flandre, par Galbert de Bruges (Collection de textes pour servir à l'étude et à l'enseignement de l'histoire, Paris 1891).

7 Zur Gründung durch den Grafen Balduin V. von Flandern im Jahr 1055 vgl. Édouard Hautcour, Histoire de l'église collégiale et du chapitre de Saint-Pierre de Lille, Bd. 1 (Lille 1896) 1-21.

8 Zur Gründung (630-639), zur Frühgeschichte und zum Wiederaufbau der Abtei Sint Baafs vgl. Adriaan Verbulst, De Sint-Baafsabdij te Gent en haar grondbezit (VIIe-XIVe eeuw), (Koninklijke Vlaamse Academie voor Wetenschappen, Letteren en Schone Kunsten van België, Klasse der Letteren 30, Brussel 1958) 3-65; im folgenden zitiert: Verhulst, Sint-Baafsabdij. Zur Gründung der Abtei Sint Pieters (nach 630-639); vgl. ders., Over de stichting en de vroegste geschiedenis van de Sint-Pieters-en de Sint-Baafs-Abdijen te Gent, in: Handelingen der Maatschappij voor Geschiedenis en Oudheidkunde te Gent, nieuwe reeks 7 (1953) 3-53. Zur Gründung der Abtei Saint-Amand d'Elnon (Saint-Amand-les-Eaux, Saint-Amand en Pévèle) vor 639 vgl. Henri Platelle, Le temporel de l'abbaye de Saint-Amand des origines à 1340 (Paris 1962) 35-37; im folgenden zitiert: Platelle, Le temporel. Zur Abtei Saint-Martin de Tournai vgl. Ursmer Berlière, L'Abbaye de Saint-Martin de Tournai, in: Monasticon Belge I (Maredsous 1890-1897, Nachdr. Liège 1961) 271-293; im folgenden zitiert: Monasticon Belge I.

9 Zur Gründung der Regularkanonikerabtei Saint-Nicolas-des-Prés vgl. zuletzt Wolfgang Gärtner, Das Chorherrenstift Klosterrath in der Kanonikerreform des 12.Jahrhunderts, in: Zeitschrift des Aachener Geschichtsvereins 97 (1991) 33-220, ebd. 42, 104; Ludo Milis, L'ordre des chanoines réguliers d'Arrouaise. Son histoire et son organisation, de la fondation de l'abbaye-mère (vers 1090) à la fin des chapitres annuels (1471), Bde. 1, 2 (Bruges 1969) 229, 490; Monasticon Belge I, 428-439. Zur Gründung eines Säkularkanonikerkapitels in Cysoing vor 867 und zur Umwandlung in eine Regularkanonikerabtei 1128 vgl. Ignace de Coussema- 


\section{,Altar' und,Person`}

Diese und andere kirchliche Institutionen in der Diözese Tournai haben während des 11. und 12.Jahrhunderts ihren Besitz an Liegenschaften und nutzbaren Rechten nicht nur verwaltet, sondern auch in teilweise erheblichem Umfang vermehrt. In den Urkunden, die anläßlich der Erwerbungen ausgefertigt worden sind, fallen zwei neue, vor dem 11.Jahrhundert nicht erscheinende Begriffe besonders auf: altare und persona. In den Bischofsurkunden und auch in nachfolgenden päpstlichen Privilegien ist im Hinblick auf den Kirchenbesitz nicht nur von ecclesiae, sondern vor allem von altaria die Rede; die altaria ihrerseits erscheinen in Verbindung mit personae. Beide Begriffe beziehen sich eindeutig auf Niederkirchen, also auf Seelsorgekirchen, die mit Pfarreirechten verbunden waren.

Die neuen Begriffe altare und persona sind der Forschung nicht entgangen. Dem Begriff altare hat man in diesem Zusammenhang allerdings keine große Aufmerksamkeit geschenkt. Man hat ihn mehr oder weniger ausdrücklich als Synonym für Pfarrkirche aufgefaßt. ${ }^{10}$ Anders verhält es sich mit dem Begriff persona. Mit ihm hat sich bereits der den Kanonisten wohlbekannte Petrus de Marca (1594-1662) beschäftigt, des weiteren Jean Mabillon in seinen Annales Ordinis Sancti Benedicti. ${ }^{11}$ Die Forschung zum Begriff persona ist in zwei Lager geteilt.

ker, Cartulaire de l'abbaye de Cysoing et de ses dépendances (Lille 1884) Nr. 1-4, 8, 9, 11. Zur Gründung der Augustinerchorherrenabtei Phalempin vgl. Nicolas Huyghebaert, „Hugo Tornacensis ecclesiae cancellarius". Examen critique de la charte de fondation de l'abbaye de Phalempin (1039), in: Bulletin de la Commission royale d'Histoire 128 (1962) 183-273.

10 Vgl. Dietrich Lohrmann, Kirchengut im nördlichen Frankreich. Besitz, Verfassung und Wirtschaft im Spiegel der Papstprivilegien des 11.-12.Jahrhunderts (Pariser Historische Studien 20, Bonn 1983) 147 mit weiteren Literaturangaben; im folgenden zitiert: Lohrmann, Kirchengut. François Louis Ganshof, Was ist das Lehnswesen? (Darmstadt 4/1975) 124. Balduinus Janssens de Bisthoven, De houders van patronaatsrecht in Westvlaamsche parochies, in: Collationes Brugenses 42 (1946) 150-161, 265-271, ebd. 151-153; im folgenden zitiert: Janssens de Bisthoven, Houders van patronaatsrecht. $R$. $R$. Post, Eigenkerken en bisschoppelijk gezag in het diocees Utrecht tot de XIIIe eeuw (Bijdragen van het Instituut voor Middeleeuwsche Geschiedenis der Rijks-Universiteit Utrecht 13, Utrecht 1928) 66 Anm. 2; im folgenden zitiert: Post, Eigenkerken. Georg Schreiber, Kurie und Kloster im 12.Jahrhundert. Studien zur Privilegierung, Verfassung und besonders zum Eigenkirchenwesen der vorfranziskanischen Orden vornehmlich auf Grund der Papsturkunden von Paschalis II. bis auf Lucius III. (1099-1181) (Kirchenrechtliche Abhandlungen 67-68, Stuttgart 1910) 2, 49-54; im folgenden zitiert: Schreiber, Kurie und Kloster. Paul Hinschius, System des katholischen Kirchenrechts mit besonderer Rücksicht auf Deutschland, Bd. 2 (Berlin 1878) 438-439. Bereits während des 11.Jahrhunderts war man sich der Tatsache bewußt, daß der Begriff altare und damit die Unterscheidung zwischen ecclesia und altare (siehe dazu unten Anm. 17) im wesentlichen auf den Herrschaftsbereich der französischen Krone beschränkt war, vgl. can. 3 des Konzils von Clermont 1095 (ed. Joannes Dominicus Mansi, Sacrorum conciliorum nova et amplissima collectio, 31 Bde., Florenz - Venedig 1759-1793, 20 902): „Quia quidam simoniacae pravitatis ramus in Galliarum partibus iam diutius inolevit, ut ecclesiae vel decimae quae vulgari vocabulo apud eos nuncupantur altaria ..." Hinsichtlich der komplizierten Uberlieferung der Canones von Clermont sei verwiesen auf Robert Somerville, The Councils of Urban II. Volume 1: Decreta Claromontensia (Annuarium Historiae Conciliorum, Supplementum 1, Amsterdam 1972); zu can. 3 vgl. ebd. 122-123.

11 Vgl. Petrus de Marca, Dissertatio ad concilium Claromontanum, Nota ad canonum VII. 
Die einen sehen in der persona die redemptio altaris, nämlich jene Praxis, beim Wechsel des Priesters an einer Eigenkirche dem Bischof eine Geldsumme zwecks weiterer Nutzung der Kirche zahlen zu müssen. ${ }^{12}$ Die anderen sehen in der persona den Pfarrer und in dem entsprechenden Abstraktum personatus das Pfarrbenefizium. Die These, die Wendungen altare absque persona oder altare libere sine persona bedeuteten die Übertragung des Pfarrbenefiziums an das Kloster, mithin die Inkorporation, ist kürzlich noch mit Nachdruck vertreten worden. ${ }^{13}$

Die Inkorporation, als Rechtsinstitut nach herrschender Meinung erst auf der

(Mansi 20 891); Johannes Mabillon, Annales Ordinis Sancti Benedicti Bd. 4 (Lucca 1739) 445: Zu dem Kanonisten Pierre de Marca vgl. Friedrich Maassen, Geschichte der Quellen und der Literatur des canonischen Rechts im Abendlande bis zum Ausgange des Mittelalters Bd. 1 (Graz 1870) XLIV-XLVIII.

12 Vgl. Post, Eigenkerken, 66-67, 78; Hinschius, Kirchenrecht 2, 439 Anm. 2. Von literaturhistorischem Interesse ist Hans Rheinfelder, Das Wort „Persona“. Geschichte seiner Bedeutungen mit besonderer Berücksichtigung des französischen und italienischen Mittelalters (Halle/Saale 1928). Jean Gaudemet, Persona, in: Cristianesimo nella storia 9 (1988) 465-492 behandelt die Bedeutung des Wortes für die christliche Kirchengemeinschaft sowie im Hinblick auf die außerhalb dieser Gemeinschaft Stehenden.

${ }_{13}$ Die These, persona bedeute Pfarrer und die Übertragung eines Altars sine persona sei die Inkorporation avant la lettre gewesen, ist zuletzt vertreten worden von Wolfgang Petke, Von der klösterlichen Eigenkirche zur Inkorporation in Lothringen und Nordfrankreich (11. und 12. Jahrhundert). Vortrag im Rahmen der Arbeitstagung des Konstanzer Arbeitskreises für mittelalterliche Geschichte über „Probleme des Niederkirchenwesens im Mittelalter“, 6.-9. Oktober 1987. Die Vorträge der Arbeitstagung sollen in der Reihe „Vorträge und Forschungen" publiziert werden. Vgl. auch in diesem Sinne Pycke, Chapitre Cathédral, 268; Daniel Lambrecht, De parochiale synode in het oude bisdom Doornik gesitueerd in de Europese ontwikkeling. $11 \mathrm{de}$ eeuw - 1559 (Verhandelingen van de Koninklijke Academie voor Wetenschappen, Letteren en Schone Kunsten van Belgie, Klasse der Letteren, Jaargang 46 Nr. 113 , Brussel 1984) 45 Anm. 130; 134-135; im folgenden zitiert: Lambrecht, Parochiale synode. Jean-Marie Duvosquel, Les chartes de donation d'autels émanant des évêques de Cambrai aux XIe-XIIe siècles éclairées par les obituaires. A propos d'un usage grégorien de la chancellerie épiscopale, in: Hommages à la Wallonie. Mélanges d'histoire, de littérature et de philologie wallones offerts à Maurice A. Arnould et Pierre Ruelle, ed. Hervé Hasquin (Editions de l'Université de Bruxelles. Faculté de Philosophie et Lettres 80, Bruxelles 1981) 147-163; im folgenden zitiert: Duvosquel, Chartes de donation. André Vanrie, Notes sur l'incorporation des églises paroissiales au moyen âge, in: Hommage au professeur Paul Bonenfant (1899-1965). Études d'histoire médiévale dédiées à sa mémoire par les anciens élèves de son séminaire à l'Université libre de Bruxelles (Bruxelles 1965) 47-55, ebd. 51. Huyghebaert, Abbés de Saint-Bertin 417-418; Milo Hendrik Koyen, De Prae-Gregoriaanse Hervorming te Kamerijk (1012-1067) (Tongerlo 1953) 179; im folgenden zitiert: Koyen, Prae-Gregoriaanse Hervorming. Janssens de Bisthoven, Houders van patronaatsrecht 151-153. Joseph Laenen, Introduction à l'histoire paroissiale du diocèse de Malines (Bruxelles 1924) 352-360. Von einer Inkorporation bei einer Übertragung absque persona ist ebenfalls implizit ausgegangen Platelle, Le temporel 151-152. Differenzierter beschreibt den Begriff persona Joseph Avril, Quelques aspects de l'institution paroissiale après le IVe concile du Latran, in: Crises et réformes dans l'église. De la réforme grégorienne à la préréforme. $115 \mathrm{e}$ Congrès National des Sociétés savantes (Avignon 1990) 93-106, ebd. 96, der unter persona einen Kleriker versteht, dem ein Niederkirchenbenefizium zur Verwaltung übertragen worden ist mit dem Recht, einen capellanus zwecks Ausübung der Seelsorge zu benennen. Dieser "système" sei während des 11. und 12. Jahrhunderts in Nord- und Ostfrankreich sowie auch in westfranzösischen Diözesen wie Angers und Le Mans praktiziert worden. 
Wende vom 12. zum 13.Jahrhundert ausgebildet, soll also in praxi bereits im 11. Jahrhundert bestanden haben.

Die Forschung hat sich bekanntlich seit der Prägung des Begriffs „Eigenkirche“ durch Ulrich Stutz am Ende des 19. Jahrhunderts um die Klärung des Verhältnisses bemüht, in dem die Eigenkirche zu den Rechtsinstituten des Patronats und der Inkorporation steht. Folgt man der kürzlich mit Nachdruck vertretenen These, so scheint das Verhältnis des Eigenkirchenbesitzes zur Inkorporation nunmehr geklärt. Der Sachverhalt läßt sich dieser These zufolge so formulieren: Hat ein Bischof einem Kloster oder einem Stift einen Altar sine persona übertragen, so liegt nicht mehr Eigenkirchenbesitz, sondern Inkorporation vor. ${ }^{14}$

\section{Altäre als Vermögensobjekte}

Bei den nordfranzösischen und flandrischen Abteien kann man nach der Jahrtausendwende im Bereich der Vermögensverwaltung einen neuen Investitionsschwerpunkt feststellen. Wie Henri Platelle für Saint-Amand d'Elnon dargetan hat, reagieren die Leiter der großen Benediktinerabteien auf den Rückgang der Landschenkungen aus Laienhand auf eine bestimmte Weise. Die Investitionspolitik richtet sich nunmehr auf den Erwerb von Niederkirchen und Altären. ${ }^{15}$ Der neue Schwerpunkt ist nicht willkürlich gewählt, sondern durch klimatische, demographische, technische und vor allem rechtliche Entwicklungen im westlichen

${ }^{14} \mathrm{Zu}$ den Schriften von Ulrich Stutz zum Rechtsinstitut der Eigenkirche sowie zur Kritik der Forschung an seinen Thesen vgl. Wilfried Hartmann, Der rechtliche Zustand der Kirchen auf dem Lande: Die Eigenkirche in der fränkischen Gesetzgebung des 7. bis 9. Jahrhunderts, in: Cristianizzazione ed organizzazione ecclesiastica delle campagne nell'alto medioevo: espansione e resistenze (Settimane di studi sull'alto medioevo 28, Spoleto 1982) 397441, ebd. 400-401; im folgenden zitiert: Hartmann, Rechtliche Zustand. Zum bisherigen Forschungsstand hinsichtlich der Rechtsinstitute der Eigenkirche, des Patronats und der Inkorporation vgl. Peter Landau, Artikel ,Inkorporation', in: Theologische Realenzyklopädie 16 (1987) 163-166, der ebd. 164 auf die Unterscheidung zwischen privatrechtlichen Geschäften bezüglich des Patronats und der hoheitlichen Gewährung der Inkorporation hinweist; im folgenden zitiert: Landau, Inkorporation.

15 Vgl. für Saint-Amand Platelle, Le temporel, 150-152, 193-194; vgl. für Sint Baafs Verbulst, Sint-Baafsabdij, 114-116. Zur Arrondierungspolitik des Kollegiatkapitels Saint-Pierre in Lille, die nicht zuletzt im gezielten Erwerb von vier Altären sowie der dazugehörigen bodia in der Zeit von 1090 bis 1110 bestand, vgl. Leon Voet, Bodium - Redecima, in: Archivum Latinitatis Medii Aevi 20 (1950) 207-244, ebd. 221-222; im folgenden zitiert: Voet, Bodium. Das Vermögen von Saint-Pierre bestand 1144 in der Hauptsache aus 25 Altären und neun Zehnten; die entsprechenden Investitionen wurden im allgemeinen in Gestalt von Zinssatzungsverträgen vorgenommen, vgl. Hans van Werveke, Le mort-gage et son rôle économique en Flandre et en Lotharingie, in: Revue belge de philologie et d'histoire 8 (1929) 53-91, ebd. 63; im folgenden zitiert: Van Werveke, Mort-gage. Die Arrondierungspolitik von Saint-Pierre trägt auch zu der Erklärung dafür bei, daß die Unterscheidung von altare und ecclesia im Laufe des 12.Jahrhunderts immer seltener wird: Die kirchlichen Institutionen arrondieren ihren Altarbesitz naheliegenderweise durch den Erwerb der entsprechenden bodia. Zu einer vergleichbaren Investitionspolitik nordfranzösischer Regularkanonikerabteien vgl. Martin Schoebel, Archiv und Besitz der Abtei St. Viktor in Paris (Pariser Historische Studien 31, Bonn 1991) 239-251; im folgenden zitiert: Schoebel, Archiv. 
Europa begründet. Auf alle diese Entwicklungen kann hier im Rahmen des gestellten Themas nicht näher eingegangen werden. ${ }^{16}$ Auf bestimmte rechtliche Entwicklungen wird jedoch im folgenden näher einzugehen sein.

Im Mittelpunkt dieser rechtlichen Entwicklungen steht der Begriff altare. Die belgische Forschung hat bereits die Bedeutung des Begriffs für diejenigen $\mathrm{Bi}$ schofsurkunden geklärt, in denen es um Niederkirchen geht. Altare meint hier die altarbezogenen Einkünfte wie Stolgebühren und Oblationen sowie ein Drittel des Zehnten, während ecclesia in diesem Zusammenhang für die restlichen beiden Zehntdrittel steht. ${ }^{17}$ In manchen flandrischen Urkunden des 11.Jahrhunderts fin-

${ }^{16}$ Hingewiesen sei hier nur knapp auf folgende Literatur: Zur „Medieval Warm Epoch“ des 10. bis 12. Jahrhunderts vgl. Peter Brimblecombe, Climate Conditions and Population Development in the Middle Ages, in: Saeculum 39 (1988) 141-148, ebd. 143. Zur Bevölkerungszunahme in Flandern seit dem 9. Jahrhundert vgl. Walter Prevenier - Adriaan Verbulst, Artikel ,Flandern', in: Lexikon des Mittelalters 4 (1989) 514-532, ebd. 524-525; Hans van Werveke, De bevolkingsdichtheid in de IXe eeuw. Poging tot schatting, in: XXXe Congres van het Oudheid-en Geschiedkundig Verbond van België. Brussel, 28 juli - 2 augustus 1935 (Brussel 1936) 107-116. Zur demographischen und zur technischen Entwicklung seit der Jahrtausendwende vgl. Adriaan Verbulst, Occupatiegeschiedenis en landbouweconomie in het Zuiden circa 1000-1300, in: Algemene Geschiedenis der Nederlanden 2 (1982) 83-99. Zum Kummet, das eine bessere Ausnutzung der Zugtierkraft bei gleicher Leistung ermöglichte, vgl. Georges Duby, Le problème des techniques agricoles, in: Agricoltura e mondo rurale (Settimane di studio del Centro Italiano di Studi sull'Alto Medioevo 13, Spoleto 1966) 267283, ebd. 280-283. Eine kleine Spezialbibliographie zum Thema Rodung und Urbarmachung bietet $J$. David, De techniek van de middeleeuwse ontginningen. Belang en onderzoekingsmethoden, in: Bronnen voor de historische geografie van België. Handelingen van het Colloquium te Brussel 25.-27. april 1979 (Brussel 1980) 317-329. Den Erfolg der Rodungs- und Urbarmachungsunternehmen in der Diözese Tournai bezeugen Neubruch- oder Novalzehnten, die erwartungsgemäß zu Rechtsstreitigkeiten und Prozessen zwischen interessierten Parteien geführt haben, vgl. dazu Inge Schoups, Bisschoppelijke aanspraken op novale tienden: Doornik, $12 \mathrm{e}-14 \mathrm{e}$ eeuw, in: Handelingen van het Genootschap voor Geschiedenis gesticht onder de benaming, Société d'émulation' te Brugge 118 (1981) 153-171. Die genannten Entwicklungen sind zu sehen vor dem Hintergrund von Pfarrbezirken, die aus heutiger Sicht enorme Dimensionen besaßen: So erstreckte sich die nördlich von Brugge gelegene Pfarrei Oostkerke, der Abtei Saint-Quentin-en-l'Ile (Diözese Noyon) gehörig, über eine Fläche von 80 Quadratkilometern; von der Pfarrkirche waren vier Filialkirchen abhängig, die nach 1163 Pfarreirechte erhielten, vgl. Janssens de Bisthoven, Houders van patronaatsrecht, 269.

17 Vgl. Édouard Hautcour, Cartulaire de l'église collégiale de Saint-Pierre de Lille Bd. 1 (Lille-Paris 1894) 4 Anm. 1; im folgenden zitiert: Hautcoeur, Cartulaire. Vgl. auch Huyghebaert, Abbés de Saint-Bertin, 417-418. Zum Altar als Leistungsort für die Oblationen vgl. Emile Amann - Auguste Dumas, L'Eglise au pouvoir des laiques (888-1057) (Histoire de l'Église depuis les origines jusqu'à nos jours 7, Paris 1943) 271; zu den Einkünften als Zubehör des jeweiligen Altars vgl. auch Wolfgang Schöller, Die rechtliche Organisation des Kirchenbaues im Mittelalter, vornehmlich des Kathedralbaues. Baulast - Bauherrenschaft - Baufinanzierung (Köln - Wien 1989) 34. Zur erstmaligen bekannten Nennung des Begriffs altare in einer bischöflichen Urkunde für die Diözese Tournai (Bischof Radbod I. von NoyonTournai für Sint Pieters in Gent 994) vgl. Nicolas Huyghebaert, Examen de la charte de Radbod Ier, évêque de Noyon et de Tournai, pour Saint-Pierre de Gand (994), in: Bulletin de la Commission Royale d'Histoire 132 (1966) 1-35, ebd. 20. Zum Altar als "Ort des Opfers" und als "Garant und Träger von Heiligkeit" aufgrund seiner Weihe vgl. Carl-Heinz Ratschow, Artikel ,Altar', in: Theologische Realenzyklopädie 2 (1978) 306-308. 
det sich auch das Wort bodium in Verbindung mit altare. Hier bezeichnet bodium die restlichen beiden Zehntdrittel. ${ }^{18}$ Mit dem Begriff altare bezeichnete man also während des 11. und 12.Jahrhunderts nicht nur den Altar einer Kirche als Sakralgegenstand und Ort der Eucharistie, sondern auch die mit diesem aufgrund der cura animarum verbundenen nutzbaren Rechte. Diese nutzbaren Rechte bezogen sich, wie erläutert, auf ein Zehntdrittel sowie auf diejenigen Abgaben der Pfarreingesessenen, die unmittelbar mit der Spendung von Sakramenten oder der Vornahme sakramentaler Handlungen verbunden waren. ${ }^{19}$

Die Altäre der Seelsorgekirchen waren folglich materiell nutzbare Sondervermögen, mit Erträgen, die aufgrund des Pfarrzwangs langfristig gesichert waren. In Anbetracht der damaligen Ausdehnung der Pfarrbezirke mußten die Altäre als Investitionsobjekte um so interessanter werden, je mehr die Bevölkerung wuchs, je größer die Flächen für landwirtschaftliche Nutzung wurden und je mehr sich die Erträge dieser Flächen aufgrund technischer Neuerungen erhöhten. ${ }^{20}$

\section{Ecclesia und altare}

Die Unterscheidung zwischen ecclesia und altare findet sich bekanntlich zum ersten Mal bei Abbo von Fleury, der von 988 bis 1004 als Abt dieses Klosters an der Loire fungierte. Es sei ein äußerst schwerwiegender Irrtum, so formulierte Abbo, eine Kirche derart zu teilen, daß der Bischof über den Altar und irgendein anderer dominus über die Kirche verfügen könne. ${ }^{21}$ In einem seiner Briefe klagt Abbo, Altäre würden durch die Entscheidung der Bischöfe an Laien besitzweise übertragen, die dann die Oblationen für den Unterhalt ihrer Pferde und Jagdhunde verwendeten. ${ }^{22}$

Die Teilung der Seelsorgekirchen unter zwei Verfügungsberechtigte, Ordina-

18 Vgl. Voet, Bodium, 207-232. Zur Übertragung des bodium de Lescin, zuvor als Lehen an Engelbert von Cysoing und den Burggrafen Roger von Lille verliehen, als perpetua allodii possessio ... ad usus canonicorum des Kollegiatkapitels Saint-Pierre in Lille vgl. Fernand Vercauteren (ed.), Actes des comtes de Flandre (1071-1128) (Commission Royale d'Histoire. Recueil des actes des princes belges 2, Bruxelles 1938) Nr. 20.

${ }_{19} \mathrm{Zu}$ Geldforderungen bei Taufe, Beichte und Begräbnis bzw. Taufe, Krankenbesuch, Begräbnis und Kommunion vgl. can. 12 des Konzils von Bourges 1031 (Mansi 19 504-505) sowie can. 5 des Konzils von Reims 1049 (a.a.O. 742).

20 Zur Ertragskraft französischer Eigenkirchen während des 12. Jahrhunderts vgl. Lohrmann, Kirchengut 148 Anm. 109a; Schoebel, Archiv, 245-247. Siehe auch oben Anm. 16. Zu einer "dritten Generation" von Landpfarreien, durch Auspfarrung in der Zeit vom 11. bis zum 13. Jahrhundert in Frankreich gebildet in Verbindung mit Rodungen und Gründungen von Städten, vgl. Gabriel Fournier, La mise en place du cadre paroissial et l'évolution du peuplement, in: Cristianizzazione ed organizzazione ecclesiastica delle campagne nell'alto medioevo: espansione e resistenze (Settimane di studi sull'alto medioevo 28, Spoleto 1982) 495563, ebd. 532-534.

21 Vgl. Abbo von Fleury, Apologeticus ad Hugonem et Rodbertum reges Francorum (Migne, PL 139 465-466).

22 Vgl. Abbo von Fleury, Epistola 10 (Recueil des historiens des Gaules et de la France 10,

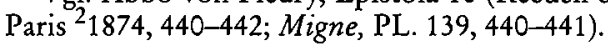


rius und dominus laicus, ist eine Etappe in der Auseinandersetzung, die seit längerem bereits zwischen den Bischöfen und den Herren der Eigenkirchen um die Verfügung über diese Kirchen geführt worden ist. Sowohl im West- wie im Ostfrankenreich haben die Bischöfe seit dem Ende des 9. Jahrhunderts auf ihren Synoden immer wieder die Forderung formuliert, Verfügungen über Kirchen und Kirchengüter in jedem Fall mit bischöflicher Zustimmung - consensus, licentia zu treffen. ${ }^{23}$ Verwiesen sei hier beispielsweise auf die Synoden von Mainz 888, Vienne 892, Ingelheim 948, Augsburg 952, Seligenstadt 1023, Bourges 1031, Reims 1049 und Poitiers 1078. ${ }^{24}$ Die Teilung der Verfügungsberechtigung zwischen dem Ordinarius und dem dominus einer Seelsorgekirche hat Paul Thomas zutreffend als „une sorte d'armistice " bezeichnet, denn es handelte sich in der Tat nur um einen "Waffenstillstand", der um die Mitte des 11.Jahrhunderts bereits enden sollte. ${ }^{25}$

${ }^{23} \mathrm{Zu}$ consensus vgl. can. 8 des Konzils von Augsburg 952 (MGH Concilia VI 194); zu licentia vgl. can. 4 des Konzils von Ingelheim 948 (ebd. 160). Vgl. auch Wilfried Hartmann, Die Synoden der Karolingerzeit im Frankenreich und in Italien (Konziliengeschichte Reihe A: Darstellungen, Paderborn u. a. 1989) 455-458; im folgenden zitiert: Hartmann, Synoden der Karolingerzeit. Zu den Bestimmungen west- und ostfränkischer Konzilien und Kapitularien des 9. Jahrhunderts hinsichtlich der Eigenkirchen vgl. Hartmann, Rechtliche Zustand, 408416, 420-436. Hingewiesen sei hier auch auf die führende Rolle des Episkopats in der Gottesfriedensbewegung des 10. und 11. Jahrhunderts, vgl. dazu Karl Ferdinand Werner, Observations sur le rôle des évêques dans le mouvement de paix aux Xe et XIe siècles, in: Mediaevalia christiana, XIe-XIIIe siècles. Hommage à Raymonde Foreville, ed. C. E. Viola (s. I. 1989) 155-195. Hingewiesen sei des weiteren auf die ebenfalls führende Rolle des Episkopats bei der Kanonikerreform des 11. und 12.Jahrhunderts, vgl. dazu Stefan Weinfurter, Neuere Forschung zu den Regularkanonikern im deutschen Reich des 11. und 12.Jahrhunderts, in: Historische Zeitschrift 224 (1977) 379-397, ebd. 391.

${ }^{24}$ Vgl. can. 5 des Konzils von Mainz 888 (Mansi 18 66); can. 4 des Konzils von Vienne 892 (a.a.O. 122); can. 4 des Konzils von Ingelheim 948 (MGH Concilia VI 160); can. 8 des Konzils von Augsburg 952 (a.a.O. 194); can. 13 des Konzils von Seligenstadt 1023 (Mansi 19398); can. 22 des Konzils von Bourges 1031 (a.a.O. 505); can. 3 des Konzils von Reims 1049 (a.a.O. 742); can. 6 des Konzils von Poitiers 1078 (Mansi 20 498). Bestimmungen zum Eigenkirchenwesen aus dem 10. und 11.Jahrhundert hat zusammengestellt Gerd Tellenbach, Libertas. Kirche und Weltordnung im Zeitalter des Investiturstreites (Forschungen zur Kirchen- und Geistesgeschichte 7, Stuttgart 1936) 112-113. Zur unterschiedlichen Haltung des Episkopats im West- und im Ostfrankenreich gegenüber dem Eigenkirchenwesen vgl. Hartmann, Rechtliche Zustand, 434-437.

$25 \mathrm{Vgl}$. Paul Thomas, Le droit de propriété des laïques sur les églises et le patronage laïque au Moyen Age (Bibliothèque de l'École des Hautes-Études. Sciences religieuses 19, Paris 1906) 76. Die Unterscheidung zwischen altare und ecclesia ist keine allgemeine Erscheinung in der westlichen Kirche, sondern auf das Gebiet der Gallia, also im wesentlichen auf das Königreich Frankreich beschränkt gewesen, wie man bereits gegen Ende des 11.Jahrhunderts auf dem Konzil von Clermont festgestellt hat (siehe dazu Anm. 10). Eine Ausnahme bildete die Diözese Cambrai, auf dem Territorium des deutschen Reiches gelegen, jedoch als Bischofssprengel zur Kirchenprovinz Reims gehörig; in dieser Diözese war die Unterscheidung ebenso geläufig wie in den Diözesen Arras und Tournai. Im Bistum Utrecht hingegen, das nördlich an die Diözese Tournai anschloß, hat die Unterscheidung bis 1131 keinen Fuß fassen können. Die Grenze für die Verwendung der beiden Begriffe scheint bis zu diesem Jahr die Diözesangrenze zwischen Tournai und Utrecht gewesen zu sein; selbst in dem Teil des 
Im übrigen entspricht die Unterscheidung zwischen altare und ecclesia bei Niederkirchen der späteren, für den Verlauf des sogenannten Investiturstreites bedeutsamen und bislang Ivo von Chartres (1090-1115/16) zugeschriebenen Unterscheidung zwischen spiritualia und temporalia. Zudem ist die Konstituierung eines Sondervermögens im Hinblick auf ein officium, hier die Ausübung der cura animarum an einer Niederkirche, ein entscheidender Schritt in der Entwicklung des beneficium ecclesiasticum gewesen. ${ }^{26}$

Bistums Utrecht, das zum Herrschaftsbereich der Grafen von Flandern gehörte, in den vier Ambachten (Quatre métiers: Boekhoute, Assenede, Axel, Hulst), haben die Bischöfe von Utrecht Kirchen ohne die Verwendung der Unterscheidung übertragen, vgl. Oorkondenboek van het Sticht Utrecht tot 1301, ed. S. Muller Fz. - A. C. Bouman, deel 1 (Utrecht 1920) Nr. 278 betreffend die Übertragung der Kirchen von Boekhoute, Assenedee und Axel sowie der Kapelle in Hulst. Vgl. ebd. passim zur Abwesenheit der Unterscheidung bis 1131; in diesem Jahr ist erstmals von altare und ecclesia die Rede. Die begriffliche und auf die Nutzung bezogene Trennung von altare und ecclesia dürfte eine Folge der recht starken Stellung des französischen Episkopats gegenüber dem König gewesen sein; demgegenüber war die Stellung der englischen und deutschen Herrscher während des 11. Jahrhunderts auch im Hinblick auf die Hochkirchen ihrer Herrschaftsgebiete erheblich stärker; vgl. zu diesem Punkt s.v. Investiturproblem in Frankreich: Lexikon des Mittelalters 5 (1991) 482. Insoweit war es dem französischen Episkopat möglich, durch Synodalbeschlüsse und durch deren Umsetzung in den einzelnen Diözesen den Einfluß der Laien auf die Niederkirchen zurückzudrängen und damit den eigenen Einfluß zu vermehren. Die Unterscheidung dürfte also eine Folge der durch entsprechenden Handlungsspielraum ermöglichten Rekuperationspolitik der französischen Bischöfe gewesen sein und bildete auch ein Teilziel dieser Politik: Laikale Niederkircheninhaber sahen sich gezwungen, den Bereich der spiritualia - das altare - dem Einfluß des kirchenrechtlich einzig Zuständigen, dem Ordinarius, zu öffnen.

26 Vgl. Uta-Renate Blumenthal, Der Investiturstreit (Stuttgart - Berlin - Köln 1982) 169170. Zu dem Nachweis, daß Ivo von Chartres nicht entscheidend zur Lösung des Investiturproblems beigetragen hat, vgl. Hartmut Hoffmann, Ivo von Chartres und die Lösung des Investiturproblems, in: Deutsches Archiv 15 (1959) 393-440, ebd. 414. Es dürfte wahrscheinlich sein, daß Ivo von Chartres bei seiner Unterscheidung von spiritualia und temporalia, dem erfolgreichen Modell zur Beendigung des Investiturstreites im deutschen Reich, inspiriert worden ist durch seine Praxis als Ordinarius der Diözese Chartres, Altäre gegen eine materielle Leistung zu vergeben. Ivo hat nämlich den Brauch der redemptio altarium nicht nur sehr gut gekannt, wie ein Schreiben an Urban II. beweist: „Multa enim inordinata fieri video in domo Dei, quae me torquent, maxime quod apud nos, qui altari non serviunt, de altari vivunt. A quo sacrilegio, cum eos absterrere velim, monendo, increpando, excommunicando, altaria a me redimere volunt sub nomine personae, sicut a praedecessoribus meis ex prava consuetudine redemerunt" (Epistola 12: Migne PL. 162, 25); Ivo hat vielmehr auch die redemptio praktiziert (siehe dazu Anm. 48). Joseph Avril, Quelques aspects de l'institution paroissiale après le IVe Concile du Latran, in: Crises et réformes dans l'église de la réforme Grégorienne à la préréforme. 115e Congrès National des Société Savante (Avignon 1990) 93-106, ebd. 93, geht davon aus, daß die Unterscheidung zwischen spiritualia und temporalia erstmalig auf dem Konzil von Clermont 1095 (can. 3 ed. Somerville) vorgenommen worden sei. Zur Frühgeschichte des beneficium ecclesiasticum wird der Verfasser vor dem 9th International Congress of Medieval Canon Law (Munich 13-18 july 1992) vortragen. 


\section{Die Rolle des Episkopats}

Der „Waffenstillstand“ zwischen den Bischöfen und den Niederkirchenbesitzern hatte schon im 10.Jahrhundert zur Folge, daß die Bischöfe die Altäre an Laien vergaben, und zwar, analog dem Lehnrecht, auf Lebenszeit gegen Zahlung eines relevium, das bald den Namen redemptio erhalten sollte. Die Laien gewährleisteten die Ausübung der Seelsorge dadurch, daß sie einem Hilfspriester - mercenarius oder conductorius - gegen eine "Eintritts"-Gebühr - introitus - und gegen eine jährliche Zinszahlung den Altar übertrugen. Der Vertrag mit dem Hilfspriester war privatrechtlicher Art; an ihm war der Ordinarius nicht beteiligt. ${ }^{27}$

Im Laufe des 11. Jahrhunderts ging die Entwicklung dahin, daß Altäre zunehmend in den Besitz von Klerikern und kirchlichen Institutionen gelangten. Dies dürfte auch eine Folge der bischöflichen Bestrebungen gewesen sein, die Herrschaft von Laien über Kleriker auf dem Wege der Altarleihe zu beseitigen. ${ }^{28}$ In der

27 Im Jahre 975 haben der Laie Eilbodo und seine Ehefrau Imma unter anderem die Ortschaft Flers-en-Escrebieu cum ecclesiis duabus der Abtei Sint Pieters in Gent ohne bischöfliche Mitwirkung übertragen, vgl. Charles Duvivier, Actes et documents anciens intéressant la Belgique (Bruxelles 1898) 333-335; im folgenden zitiert: Duvivier, Actes et documents. Demgegenüber spricht Abbo von Fleury in seinem zitierten Brief (siehe Anm. 22) von altaria laicis in possessionem dantur und geht dabei von einer Mitwirkung des Ordinarius aus. $\mathrm{Zu}$ Laien als personae vgl. Ernest Champeaux, Quelques observations qui doivent précéder une étude du personat au XIe siècle, in: Mélanges Paul Fournier (Paris 1929) 53-69, ebd. 59. Zu altaria als Lehen während des 10. und 11.Jahrhunderts vgl. François Louis Ganshof, Was ist das Lehnswesen? (4. Aufl., Darmstadt 1975) 124; Koyen, Prae-Gregoriaanse hervorming, 158-159. $\mathrm{Zu}$ einer präzisen Definition des Begriffs redemptio vom Beginn des 12. Jahrhunderts vgl. Léon Mirot (ed.), La chronique de Morigny (1095-1152) (Collection de textes 41, 2. Aufl., Paris 1912) 42. Zu Beispielen für Summen, die als redemptio gezahlt worden sind, vgl. den ansonsten mit Vorsicht zu verwendenden Beitrag von Champeaux, Quelques observations, 66. Zum Einsatz von Hilfspriestern vgl. Dominikus Lindner, Die Anstellung der Hilfspriester. Eine kirchenrechtsgeschichtliche Untersuchung (Münchener Studien zur historischen Theologie 3, Kempten 1924) 23-32; im folgenden zitiert: Lindner, Anstellung der Hilfspriester. Zum sacerdos mercenarius vgl. Joseph Laenen, Introduction à l'histoire paroissiale du diocèse de Malines (Bruxelles 1924) 388-390; zu den conductorii oder mercenarii vgl. auch Stefan Weinfurter, Salzburger Bistumsreform und Bischofspolitik im 12. Jahrhundert (Köln - Wien 1975) 186 mit Anm. 376. Zum introitus als Abgabe an den Eigenkirchenherrn anläßlich der Übertragung einer Kirche vgl. can. 4 des Konzils von Vienne 892 (Mansi 18 122); vgl. auch Michel Aubrun, La paroisse en France des origines au XVe siècle (Paris 1986) 80. Bereits Erzbisch of Hincmar von Reims hatte in seiner Schrift De ecclesiis et capellis, kurz vor 860 auf Bitten Karls des Kahlen verfaßt, die Geldzahlungen der Priester an die Eigenkirchenherren als simonistische Praxis gekennzeichnet, vgl. Hartmann, Rechtliche Zustand, 432 mit weiteren Belegen.

${ }_{28}$ Zur Übertragung von Kirchengut durch Laien vgl. die materialreiche und anschauliche Darstellung von Guillaume Mollat, La restitution des églises privées au patrimoine ecclésiastique en France du IXe au XIe siècle, in: Revue historique de droit français et étranger (4e série) 27 (1949) 399-423; im folgenden zitiert: Mollat, Restitution des églises. Vgl. auch Henri Platelle, Les paroisses du décanat de Lille au Moyen Age, in: Mélanges de science religieuse 25 (1968) 67-88, ebd. 72-73. Zur Übertragung von sieben Altären durch Kathedralkanoniker an das Kathedralkapitel von Tournai zwecks Schaffung neuer Präbenden vgl. Pycke, Chapitre Cathédral 179. Zum Einfluß der "Kirchenreform des 11.Jahrhunderts auf die Bereitschaft zur Übertragung von Altären vgl. Augustin Fliche, La Réforme grégorienne et la Reconquête 
Folge sieht man die Bischöfe, die nunmehr ihre Mitwirkung bei der Übertragung von Altären durchgesetzt haben, auf dem Weg zum nächsten Etappenziel: Jetzt galt es, im Bereich des Niederkirchenwesens die Herrschaft von Laien über Kleriker der eigenen Diözese zu beseitigen, konkurrierte doch diese Herrschaft mit dem bischöflichen Direktionsrecht über alle Kleriker des Sprengels. Den Idealzustand bischöflicher Leitungsgewalt konnten die Ordinarien seit dem Beginn des 11.Jahrhunderts ohne Mühe aus einer weitverbreiteten Kirchenrechtssammlung ersehen, die alle einschlägigen Kanones altkirchlicher Provenienz enthielt: aus dem Decretum des Bischofs Burchard von Worms (1000-1025). ${ }^{29}$

Bislang ist man davon ausgegangen, daß die päpstliche Kurie in der Auseinandersetzung um den Laieneinfluß auf kirchliche Ämter und Güter führend gewesen sei. Das Papsttum habe mit dem sogenannten Investiturverbot in dem Schreiben Nikolaus II. Vigilantia universalis, auch bekannt als 6. Absatz von Jaffé-Löwenfeld 4405/4406, eine Art Vorreiterrolle übernommen. Die hier vorgetragenen Ausführungen über das bischöfliche Handeln dürften jedoch gezeigt haben, daß die Initiative vielmehr beim französischen Episkopat gelegen hat. Die Kurie reagierte mit der Beratung über ein Investiturverbot auf eine Entwicklung, die in Frankreich seit längerem begonnen hatte und die im Hinblick auf die Beseitigung des Laieneinflusses schon weit fortgeschritten war. ${ }^{30}$ Was den Erwerb und den Be-

chrétienne (1057-1123) (Histoire de l'Église 8, Paris 1940) 411-412. Zur Bekämpfung des Eigenkirchenrechts in bezug auf die Niederkirchen während des 11.Jahrhunderts vgl. Peter Landau, Ius patronatus. Studien zur Entwicklung des Patronats im Dekretalenrecht und der Kanonistik des 12. und 13. Jahrhunderts (Forschungen zur kirchlichen Rechtsgeschichte und zum Kirchenrecht 12, Köln - Wien 1975) 3-4. Einen Beleg für den Umstand, daß Altäre zunehmend im Besitz von Klerikern nachzuweisen sind, bietet can. 2 des Konzils von Reims 1049 (Mansi 19 741-742): Der Kanon geht bereits von dem Kauf eines Altars durch einen Kleriker als Regelfall aus. Zu den Gründen für die Tatsache, daß während des 11. und 12. Jahrhunderts zumeist Kanoniker von Kathedralkirchen als Veräußerer von Altären auftreten, vgl. Duvosquel, Chartes de donation 153. Ders. bietet ebd. 162 auch ein Beispiel für das gegen Ende des 11.Jahrhunderts bereits vorhandene Unrechtsbewußtsein bei manchen Laien, die Kirchen besaßen: Graf Balduin II. von Hennegau nimmt 1090 die "Rückgabe" eines Altars an Bischof Gerhard II. von Cambrai vor, den er contra canonum decreta besessen habe.

29 Vgl. den Druck des Decretum bei Migne, PL. 140, 537-1058. Zur Überlieferung und Verbreitung des Decretum vgl. zuletzt Max Kerner, Artikel ,Burchard von Worms: Kirchenrechtliche Sammlung und Hofrecht', in: Lexikon des Mittelalters 2 (1983) 947-951 mit Bibliographie. Vgl. auch die Ausführungen von Charles Dereine, Gérard, évêque de Thérouanne (1083-1096) face aux moines exempts. Le cas des prieurés de Nieppe, Andres et Framecourt, in: Mémoires de la Société d'histoire de Comines-Warneton et de la région 10 (1980) 249-263, ebd. 263 mit Anm. 70 zur Restauration der bischöflichen Leitungsgewalt während der Pontifikate Leos IX. und vor allem Urbans II.

${ }^{30}$ Zur Vorreiterrolle des gallischen Episkopats in der Auseinandersetzung um die Niederkirchen vgl. Georg Schreiber, Gregor VII., Cluny, Citeaux, Prémontré zu Eigenkirche, Parochie, Seelsorge, in: ZRG KA 34 (1947) 31-171, ebd. 59-63; im folgenden zitiert: Schreiber, Gregor VII. Von einer Sonderstellung des can. 6 der Lateransynode 1059 im Rahmen des Prozesses, die Niederkirchen der Nutzung durch Laien zu entziehen, geht aus Hartmann, Synoden der Karolingerzeit, 453. Zum sogenannten Investiturverbot in can. 6 der Lateransynode 1059 (JL 4405/4406) vgl. ausführlich Rudolf Schieffer, Die Entstehung des päpstli- 
sitz von Altären durch kirchliche Institutionen betrifft, so haben die von der $\mathrm{Ku}$ rie initiierten Beschlüsse diesen Erwerb keineswegs ausgelöst, sondern lediglich akzentuiert. $^{31}$

Anhand von Urkunden des 11.Jahrhunderts aus der Diözese Tournai kann man, betreffend die Übertragung von Altären, folgende Lage feststellen: Wenige Altäre befinden sich noch im Besitz von Laien, die Masse der Altäre hingegen gehört Klerikern. In zunehmendem Maße erwerben nun kirchliche Institutionen Abteien und Kollegiatkapitel - aufgrund des neuen Investitionsschwerpunktes die Altäre von diesen Laien oder Klerikern, und zwar unter bischöflicher Mitwirkung. Wie noch zu zeigen sein wird, handelt es sich bei diesen Altarübertragungen um dreiseitige Rechtsgeschäfte; der Ordinarius ist gleichberechtigte Partei. ${ }^{32}$

\section{Die personae}

Die Kleriker, die Altäre übertragen, werden in den Urkunden als personae bezeichnet. Häufig wird auch der Verkäufer nicht genannt, und es ist lediglich von altare cum persona die Rede. ${ }^{33}$ Die bisherige Forschung hat zutreffend festgestellt,

chen Investiturverbots für den deutschen König (Schriften der Monumenta Germaniae Historica 28, Stuttgart 1981) 48-84. Im übrigen ist der in can. 6 gemeinte Sachverhalt bereits in can. 21 des Konzils von Bourges 1031 (Mansi 19 505) und in can. 2, 3 des Konzils von Reims 1049 (a.a.O. 741-742) formuliert.

31 Vgl. Duvosquel, Chartes de donation, 161-162. Aufschlußreich ist auch die Tatsache, daß die päpstliche Kanzlei die Altäre und Kirchen den kirchlichen Institutionen nur als possessiones und unter dem Vorbehalt des bischöflichen Verfügungsrechts (concessione pontificum) bestätigt hat, vgl. Lohrmann, Kirchengut, 45.

${ }^{32}$ Bereits das Konzil von Reims 1049 ging in can. 2 ( Mansi 19 741-742) vom Altarbesitz in Klerikerhänden aus, als man die Rückgabepflicht für die von Klerikern gekauften ministeria uel altaria an den Ordinarius forderte. Wie bereits Lambrecht, Parochiale synode, 29 festgestellt hat, setzt die bischöfliche Mitwirkung bei der Übertragung von Altären in der Diözese Tournai mit dem Pontifikat Radbods II. von Noyon-Tournai (1068-1098) ein. Für die Diözese Cambrai hat Duvosquel, Chartes de donation, 148 ermittelt, daß seit den letzten Jahren des 11.Jahrhunderts Laien nicht mehr als Veräußerer von Altären genannt werden; zu Laien als Veräußerern von Altären während der zweiten Hälfte des 11.Jahrhunderts vgl. ebd. 153. $\mathrm{Zu}$ nordfranzösischen Pfarrkirchen in Laienhand während der ersten Hälfte des 12. Jahrhunderts vgl. Schoebel, Archiv, 240-241. Zu tatsächlich dreiseitigen, jedoch als zweiseitig beurkundeten Rechtsgeschäften mit Altären vgl. Duvosquel, a.a.O. 155. Vgl. im übrigen zum Ordinarius als Mitwirkungsberechtigten bei der Übertragung von Kirchen can. 14 des Dritten Laterankonzils (Conciliorum oecumenicorum decreta, ed. Joseph Alberigo u.a., 3. Aufl. (Bologna 1973) 218-219). Die Entwicklung hinsichtlich der Übertragung von Altären war um das Jahr 1300 abgeschlossen: Von den 265 Pfarrkirchen Flanderns gehörten um diese Zeit 235 einer kirchlichen Institution, 7 gehörten einem Laienpatron, und 23 waren der libera collatio des Ordinarius unterworfen, vgl. Janssens de Bisthoven, Houders van patronaatsrecht, 271.

${ }^{33} \mathrm{Zu}$ acht Altären, die $s u b$ personatu, oder, wie der Kontext besagt, cum personis übertragen werden, vgl. Bischof Lambert von Noyon-Tournai für Sint Baafs in Gent 1121 (Cyriel Vleeschouwers, De oorkonden van de Sint-Baafsabdij te Gent 819-1321), II. Uitgave (Koninklijke Commissie voor Geschiedenis, Brussel 1990) Nr. 21; im folgenden zitiert: Vleeschouwers, Oorkonden van de Sint-Baafsabdii. 
das mit dem altare das Pfarrbenefizium gemeint ist, sie hat nicht zutreffend formuliert mit der Behauptung, persona bezeichne den "amtierenden Pfarrer“, also den an der Niederkirche tätigen Seelsorgepriester. ${ }^{34}$ Wenn in einer Urkunde des Bischofs Walter von Tournai der Archidiakon Robin als persona des Altars von Manlinnehem (Maldegem) bezeichnet wird, dann hat Robin als Archidiakon und Kanoniker des Kathedralkapitels mit Sicherheit nicht in der Seelsorgekirche von Maldegem die Altaroblationen eigenhändig entgegengenommen, Kranken das Viaticum gebracht und Wöchnerinnen ausgesegnet. ${ }^{35}$ Wenn in einer anderen Urkunde eindeutig unterschieden wird zwischen der persona und den presbiteri, die nullo medio die Kirche "bedienen" - deseruire - sollen, dann wird deutlich, daß die persona nicht mit dem Seelsorgepriester gleichgesetzt werden darf. Das schon von den Laien des 10. Jahrhunderts beobachtete Verfahren, im Wege des Privatvertrages einen Hilfspriester mit der Ausübung der Seelsorge zu beauftragen, ist sicherlich auch von den Kleriker-personae gehandhabt worden. Dem bekannten Brief Ivos von Chartres an Papst Urban II. zufolge scheint die Übertragung der Seelsorgeverpflichtung eine Selbstverständlichkeit gewesen zu sein, klagt Ivo doch über die personae, die nach der redemptio eines Altars diesen nicht selbst bedienen, aber von ihm leben wollen. ${ }^{36}$

34 Zur bisherigen Forschung vgl. die Ausführungen bei den Anm. 10-13. Die thèse von Bernard Delmaire, Le diocèse d'Arras du XIe au XIVe siècle, die auch ausführlich auf „le système du ,personnat " " eingeht, war mir nicht zugänglich. Wie der Verfasser freundlicherweise mitgeteilt hat, wird die Druckfassung voraussichtlich 1993 erscheinen.

${ }^{35}$ Zur Edition der Urkunde von 1170 vgl. Vleeschouwers, Oorkonden van de Sint-Baafsabdij, Nr. 54. Bei Robinus Tornacensis aecclesiae archidiaconus handelt es sich um Robert de Courtrai, Archidiakon von Flandern 1169-1183, vgl. Jacques Pycke, Répertoire biographique des chanoines de Notre-Dame de Tournai, 1080-1300 (Université de Louvain - Recueil de travaux d'histoire et de philologie 35, Louvain-la-Neuve - Bruxelles 1988) 55-56. Zu Maldegem (östlich Brugge, provincie Oost-Vlaanderen, Belgien) vgl. Maurits Gysseling, Toponymisch Woordenboek van België, Nederland, Luxemburg, Noord-Frankrijk en WestDuitsland vóór 1226 (s. 1. 1960) 654. Zu der Kapelle und späteren Propstei Papinglo in Maldegem, der Abtei Sint Baafs in Gent gehörig, vgl. Monasticon Belge 7,2 (1977) 129-132. Zu Terminen für Oblationen und zu Anlässen für Stolgebühren vgl. Bischof Walter von Tournai für Sint Baafs in Gent 1169 (wie Anm. 49). Zu den Oblationen vgl. ausführlich Schreiber, Kurie und Kloster 2, 92-104; Ders., Gregor VII., 67-87. Zum geringen Ansehen der Seelsorgepriester während des 12. Jahrhunderts vgl. das auf Veranlassung seines Kathedralkapitels ausgefertigte Mandat des Bischofs Heinrich von Senlis 1180 betreffend die Inkompatibilität von Kanonikat und Pfarrseelsorge (Gallia Christiana 10, Instrumenta, 436-437): Bischof Heinrich verweist darauf, daß die Einsegnung von Ehebetten, die Rekonziliation von Wöchnerinnen, die Berichtspflicht über Streitigkeiten an den Ordinarius sowie die Unterordnung unter den Landdekan mit der Würde eines Kanonikers unvereinbar seien. Zu dem Kathedralkanoniker von Tournai Wericus als Inhaber des personatus und der cura (sc. animarum) des Altars von Esplechin vgl. Bischof Balderich von Noyon-Tournai für Saint-Martin de Tournai 1103, ed. Armand d'Herbomez, Chartes de l'abbaye de Saint-Martin de Tournai 1 (Bruxelles 1898) Nr. 5; im folgenden zitiert: d'Herbomez, Chartes de Saint-Martin. Zu dem Scholaster des Kathedralkapitels von Cambrai und bischöflichen Kanzler Werinboldus sowie zu dem Kathedralkanoniker Hugo als personae verschiedener Altäre vgl. Duvosquel, Chartes de donation, 159.

${ }_{36} \mathrm{Zu}$ den personae und deren presbyteri vgl. Johannes Ramackers, Papsturkunden in den 
Somit ist man nun in der Lage, den Begriff persona in den Bischofsurkunden Flanderns und des Artois zu definieren. Die persona war eine natürliche Person männlichen Geschlechts, die nach der Übertragung des altare gegen Zahlung der redemptio berechtigt war, die Altareinkünfte unbeschränkt und gegebenenfalls bis an das Lebensende zu nutzen. Die persona war des weiteren verpflichtet, die mit dem Altar verbundene cura animarum auszuüben. War die persona nicht willens oder in der Lage, der Seelsorgeverpflichtung nachzukommen, so konnte sie diese Pflicht privatrechtlich einem Seelsorgepriester übertragen; dieser war seinerseits berechtigt zur Nutzung der Altareinkünfte nach Maßgabe der persona. Die cura animarum empfing der Hilfspriester von dem zuständigen Ordinarius oder per Subdelegation von demjenigen, der bereits die cura erhalten hatte. Die Verpflichtung, die gewohnheitsrechtlich festgelegten Abgaben an den Ordinarius - cathedraticum, synodaticum, obsonium, procuratio canonica - zu zahlen, verblieb bei der persona als dem Inhaber des Altars. Schließlich verfügte die persona - neben dem Recht zur Anstellung eines Seelsorgepriesters - insoweit über ein Präsentationsrecht für den in Besitz gehaltenen Altar, als es ihr freistand, unter Einbeziehung des zuständigen Ordinarius einen Übertragungsvertrag mit jemandem zu schließen und auf diese Weise den nächsten Inhaber des Altars zu bestimmen. ${ }^{37}$

Niederlanden (Belgien, Luxemburg, Holland und Französisch-Flandern) 2 (Abhandlungen der Gesellschaft der Wissenschaften zu Göttingen, Philologisch-historische Klasse, 3. Folge Nr. 9, Berlin 1934) Nr. 365 (Littera Celestins III. für die Abtei Afflighem 1196, JL -). Zu den Hilfspriestern siehe Anm. 27. Die Klage über die personae findet sich bei Ivo von Chartres, Epistola 12 (Migne, PL. 162, 25; Jean Leclercq, Ives de Chartres. Correspondance 1 (10901098) (Paris 1949) 52).

37 Zur persona als einem Kleriker oder Laien, „welcher zwar die Einkünfte der Pfarrstelle bezog und gleichsam die Rolle des Pfarrers ... spielte, nicht aber das Amt desselben ausübte, weil er nicht die höheren Weihen erwerben wollte oder konnte", vgl. Heinrich Schäfer, Pfarrkirche und Stift im deutschen Mittelalter (Stuttgart 1903) 73. Zur Möglichkeit des Ordinarius, die Übertragung der cura animarum wie im übrigen auch andere bischöfliche Amtshandlungen zu delegieren, vgl. Schreiber, Kurie und Kloster 2, 60. Für die persona bestand auch, sofern sie selbst zumindest die Subdiakonweihe empfangen hatte, die Möglichkeit, sich die cura plebis übertragen zu lassen und diese dann an den eingestellten Hilfspriester per Subdelegation zu übertragen, vgl. ebd. 55, 60-61. In der Diözese Cambrai war es gegen Ende des 12.Jahrhunderts üblich, daß die personae dem Ordinarius diejenigen Priester zwecks Übertragung der cura animarum präsentierten, die an ihrer Stelle den Altar respektive die Kirche zu bedienen hatten, vgl. can. 17 der Precepta synodalia des Bischofs Roger de Wavrin, ed. Josepb Avril, Les precepta synodalia de Roger de Cambrai, in: Bulletin of Medieval Canon Law 2 (1972) 7-15, ebd. 11. Zu einer Erläuterung der episcopalia et synodalia iura vgl. d'Herbomez, Chartes de Saint-Martin 1 Nr. 9. Zu den Abgaben an den Ordinarius und dessen nachgeordnete Amtsträger bereitet Daniel Lambrecht eine Studie vor, vgl. ders., Parochiale synode, $28 \mathrm{Anm}$. 29. Zur Leistungspflicht der persona für die iura episcopalia vgl. Huyghebaert, Examen de la charte, 20; zu einem Beispiel für diese Leistungspflicht siehe auch bei Anm. 43. Leistungspflichtig für die redemptio war im allgemeinen derjenige, dem das Benefizium zwecks Nutzung übertragen werden sollte, mithin die persona; vgl. beispielsweise Bischof Radbod II. von Noyon-Tournai für Saint-Pierre in Lille betreffend die Ubbertragung der Altäre von Gits 1088 März 16 und Wervicq 1090 Februar 19 (Hautcoeur, Cartulaire, Nr. 6, 7). Die persona als Altarinhaberin war zur Ausübung der Seelsorge nicht verpflichtet und besaß insoweit ein Präsentationsrecht für die Seelsorgerstelle. Deshalb dürfte 
Seit Beginn des 12.Jahrhunderts tritt in zunehmendem Maße das Abstraktum personatus an die Stelle von persona. ${ }^{38}$ In der Vorstellung der Zeitgenossen scheint sich eine Änderung dahingehend vollzogen zu haben, daß man nicht mehr die konkrete lebende Person sah, die als solche zur Nutzung der Altareinkünfte berechtigt war. Vielmehr traten offenbar die Einkünfte in den Vordergrund, die zur Sicherung einer Funktion auf eine Vermögensmasse radiziert waren.

\section{Die Frage der Inkorporation}

Wenn es sich bei dem personatus um das Recht auf Nutzung des Benefiziums handelt, das dem Altar einer Seelsorgekirche fest zugeordnet war, wie hat man dann die Formulierung tradidi altare libere et absque personatu in einer Bischofsurkunde für eine kirchliche Institution Flanderns zu verstehen?

Die bisherige Forschung ist hier einer Meinung: Hier sei dem Kloster oder dem Stift das Benefizium übertragen worden. Hier habe folglich eine Inkorporation stattgefunden, gemäß der Definition: „Inkorporation oder Einverleibung ist im kanonischen Recht die dauernde Vereinigung einer Pfarrei mit einem Kloster, einem Dom- oder Stiftskapitel oder einem bischöflichen Stuhl ${ }^{\text {" }}{ }^{39}$ Aufgrund der Inkorporation sei die kirchliche Institution zum parochianus perpetuus geworden, habe das Benefizialvermögen vollständig nutzen und den mit der Seelsorge beauftragten uicarius mit einem festen Einkommen, der portio congrua, abfinden können. Da nun die Übertragung des Personates schon während des 11.Jahrhunderts beurkundet worden sei, könne das Rechtsinstitut der Inkorporation nicht erst zu Beginn des 13. Jahrhunderts, sondern müsse zu Beginn des 11.Jahrhunderts entwickelt worden sein. ${ }^{40}$

ein Zusammenhang bestehen zwischen diesem Sachverhalt und dem Umstand, daß das Wort personatus im Verlauf des 12. Jahrhunderts ein Terminus technicus für das Präsentationsrecht wird, vgl. beispielhaft Alexander III. für die Abtei Saint-Bertin (1163) Mai 26 (Paris, Bibliothèque Nationale, Collection Moreau, tome 72 fol. 129rv; Johannes Ramackers, Papsturkunden in Frankreich, Neue Folge 3 (Abhandlungen der Gesellschaft der Wissenschaften zu Göttingen, Philologisch-historische Klasse, Dritte Folge Nr. 23, Göttingen 1940) Nr. 55 (Protokoll), JL 10866).

38 Vgl. Bischof Radbod II. von Noyon-Tournai betreffend Onze Lieve Vrouwe in Brugge 1094 (Gallia Christiana 5, Instrumenta 354: „... Bernerus siquidem clericus et Gummarus, qui altare illud diu sub personatu habuerant" "); Bischof Balderich von Noyon-Tournai für Saint-Quentin-en-l'Ile 1110 (Duvivier, Actes et documents 323: „liberrima traditione absque personatu"); Calixt II. für Saint-Amand 1119 (Joannes Franciscus Foppens, Auberti Miraei opera diplomatica et historica 2 (Bruxelles ${ }^{2} 1723$ ) 1155: „ab omni personatu libera“). Der früheste mir bekannte Beleg für personatus in Verbindung mit einem Altar findet sich in der Urkunde des Bischofs Balduin von Thérouanne für die Abtei Saint-Bertin 1026, ed. B. Guérard, Cartulaire de l'abbaye de Saint-Bertin (Paris 1841) Nr. II, 7. Wichtig ist der Hinweis von Schreiber, Kurie und Kloster, 251 auf die Mehrdeutigkeit des Wortes personatus: Während der Reformzeit als Abstractum des Wortes persona in Gebrauch, wird personatus bezeichnenderweise im Zuge der Herausbildung des Patronats auch für dieses Institut verwendet. 39 Vgl. Peter Landau, Artikel, Inkorporation', in: Theologische Realenzyklopädie 16 (1987) 163.

40 Siehe bei Anm. 13. 
Diese Argumentation hat zwar eine bemerkenswerte Suggestivkraft, bedarf jedoch der Korrektur.

Als erstes fällt an dieser Argumentation auf, daß die Existenz der Inkorporation seit dem 11.Jahrhundert sowohl der kanonistischen Wissenschaft des 12. Jahrhunderts als auch dem Dekretalenrecht der Kurie völlig entgangen sein müßte. Dies ist aus folgendem Grunde äußerst unwahrscheinlich: Die päpstliche Kurie wurde, nicht zuletzt von kirchlichen Institutionen der Diözese Tournai, seit dem Pontifikat Urbans II. zunehmend für Privilegierungen in Anspruch genommen. ${ }^{41}$ Vorlage für die Papstprivilegien waren die Bischofsurkunden, in denen seit dem Beginn des 12.Jahrhunderts des öfteren von altaria sine persona die Rede ist. ${ }^{42}$ Müßte nicht die Kurie, der genannten Inkorporationsthese zufolge, Formulierungen sozusagen blindlings übernommen haben, über deren Inhalt sie keinerlei Klarheit besaß?

\section{Der Fall des Altars von Aardenburg}

Doch nun zu einem Beispiel, aus dem der tatsächliche Sachverhalt hinsichtlich der Formulierung altare sine persona hervorgeht.

1096 beurkundet Bischof Radbod von Noyon-Tournai auf Bitten des Abtes Adelard von Sint Baafs in Gent dieser Abtei die Befreiung des altare de Roddenburg (heute Aardenburg) sowie der von diesem abhängigen Kapellen auf der Insel Wulpen von Abgaben an den Ordinarius, insbesondere bei Schenkungen von Dritten an den Altar, mit folgenden Auflagen: Die persona des Altars muß an der Diözesansynode teilnehmen, und es müssen jährlich zehn solidi an den Bischof

41 Zur Entwicklung der päpstlichen Delegationsgerichtsbarkeit seit der Mitte des 11.Jahrhunderts vgl. Dietrich Lobrmann, Papstprivileg und päpstliche Delegationsgerichtsbarkeit im nördlichen Frankreich zur Zeit der Kirchenreform, in: Proceedings of the Sixth International Congress of Medieval Canon Law (Monumenta iuris canonici, Series C: Subsidia, vol. 7, Città del Vaticano 1985) 535-550; Ludwig Falkenstein, Appellationen an den Papst und Delegationsgerichtsbarkeit am Beispiel Alexanders III. und Heinrichs von Frankreich, in: Zeitschrift für Kirchengeschichte 97 (1986) 36-65, ebd. 37-43. Die Reisen an die Kurie in Justizsachen wurden von den kirchlichen Institutionen zunehmend dazu genutzt, Gnadenbriefe und Privilegien zum Zweck der Bestätigung von Besitzungen und Rechten zu erwirken. Von kirchlichen Institutionen in der Diözese Tournai wurden päpstliche Privilegien in dichterer Folge seit dem Ende des 11. Jahrhunderts impetriert.

$42 \mathrm{Vgl}$. Lobrmann, Kirchengut, 34, 40. Päpstliche Privilegien wurden nicht zuletzt deshalb zusätzlich zu den Bischofsurkunden impetriert, um Rückgabeforderungen vormaliger laikaler Altar- und Kirchenbesitzer besser entgegentreten zu können, vgl. Mollat, Restitution des églises, 418-419. Ein aufschlußreiches Beispiel für das Verhältnis von Bischofsurkunden zu den darauf beruhenden Papstprivilegien bietet die Urkunde des Bischofs Balderich von Noyon-Tournai für Sint Donatiaan in Brugge 1108 (Brugge, Bisschoppelijk archief A $127 \mathrm{fol}$. 59rab) im Vergleich zu dem Privileg Paschalis' II. für Sint Donatiaan 1110 Oktober 16 (Migne PL. 163, 279, JL 6277): Die präzise Regelung hinsichtlich der personatus der übertragenen Altäre im Kontext der Bischofsurkunde ist von der päpstlichen Kanzlei nicht in das Privileg übernommen worden. Die Zahl der Beispiele für die größere Ausführlichkeit und Genauigkeit der Bischofsurkunden gegenüber päpstlichen Bestätigungen ließe sich leicht vermehren. 
sowie dieselbe Summe in mutatione personae an diesen gezahlt werden. An den Archidiakon sind die gewohnten Abgaben anläßlich des alle vier Jahre stattfindenden Sendgerichts zu zahlen. ${ }^{43}$

Hier liegt also der Fall eines Altars vor, dessen Besitz einer kirchlichen Institution bestätigt wird, sowie eine mit dem Altar verbundene persona und die Praxis der redemptio. Aufgeführt sind auch die wiederkehrenden Leistungen an den Bischof und an den Archidiakon als nachgeordneten Amtsträger, die der Ordinarius als Aussteller der Urkunde selbstverständlich in deren Kontext hat aufnehmen lassen. Gegenstand des Rechtsgeschäftes ist der Verzicht des Ordinarius auf Leistungen, die ihm bislang insbesondere bei Schenkungen an die Kirche von Aardenburg und die Kapellen des Pfarrbezirks geschuldet worden sind. Der Verzicht erstreckt sich jedoch nur auf Leistungen vom Vermögen und insbesondere von Vermögensvermehrungen; er erstreckt sich nicht auf die jährliche Zahlung in signum subiectionis (catbedraticum), weiterhin nicht auf die materielle Gegenleistung für die Ausübung des bischöflichen Rechts, das Benefizium zu übertragen (redemptio), und schließlich nicht auf die materielle Gegenleistung für die Ausübung der Sendgerichtsbarkeit (sumptus, impensa, procuratio). Die persona des altare de Roddenburg war also verpflichtet zu jährlichen Zahlungen an den Bischof und zu vierjährlichen Zahlungen an den Archidiakon; dieser periodisch wiederkehrenden Leistungspflicht muß folglich ein Nutzungsrecht am Altarvermögen gegenübergestanden haben.

Welches Recht hat nun die Abtei Sint Baafs in Verbindung mit dem Altarbesitz innegehabt? Eine Möglichkeit kann man ausschließen: Sint Baafs hat kein nullum ius besessen, kein leeres Besitzrecht ohne jeden materiellen Nutzen. ${ }^{44}$ Wenn Sint Baafs, wie im übrigen zahlreiche andere Abteien und Kollegiatkapitel Flanderns

${ }^{43}$ Edition der Urkunde bei Maurits Gysseling - A. C. F. Koch, Diplomata belgica ante annum millesimum centesimum scripta 1 (s. 1. 1950) Nr. 143. Zu Rodenburg, heute Aardenburg (östlich Brugge, provincie Zeeland, Niederlande) vgl. Gysseling, Toponymisch Woordenboek 33. $\mathrm{Zu}$ den Kapellen und späteren Pfarreien auf der Insel Wulpen - Oostende-Wulpen (Sint Lambrecht), Westende-Wulpen (Sint Precatuskerke), Briele/Avenkerke, Remboudsdorpe vgl. $M . K . E$. Gottschalk, Historische geografie van Westelijk Zeeuws-Vlaanderen I: Tot de St-Elisabethsvloed van 1404 (Sociaal geografische studies 3, Assen 1955) 5; im folgenden zitiert: Gottschalk, Historische geografie. Die Kirche in Aardenburg („in pago Flandrinse in Rodenburgh mater aecclesia cum capella et omnibus appendiciis") ist bereits zum Jahr 966 im Besitz von Sint Baafs nachzuweisen, vgl. Verhulst, Sint-Baafsabdii, 75, 461. Zu den Motiven für das Verschweigen der Gegenleistungen an die Altar- und Kirchenveräußerer vgl. Mollat, Restitution des églises, 416.

44 Zahlreiche Beispiele für die langfristige und gewinnorientierte Kapitalanlagepolitik kirchlicher Institutionen Flanderns während des 11. bis 13. Jahrhunderts bietet Van Werveke, Mort-gage, 59-66, 78-91. Auch bei sogenannten „Schenkungen“ wahrten kirchliche Institutionen ihre materiellen Interessen: So "schenkte " die Abtei Saint-Amand d'Elnon auf Bitten des Bischofs Simon von Noyon-Tournai der Abtei Ourscamp (Diözese Noyon) im Jahre 1134 einige Ländereien. Das Chartular von Ourscamp enthüllt jedoch den Hintergrund der „Schenkung", indem dort im Text der Schenkungsurkunde vermerkt wird, daß Saint-Amand 1133 als Gegenleistung den Altar von Mouchin (südöstlich Tournai, dép. du Nord, Frankreich) vom Bischof erhalten habe, vgl. Platelle, Le temporel, 192-193, mit Verweis auf $M$. Peigné-Delacour, Cartulaire de l'abbaye de Notre-Dame d'Ourscamp (Amiens 1865) Nr. 30. 
und des Artois, seit dem 11.Jahrhundert Altäre besessen und weitere erworben hat, dann müssen diese Altäre auch in Verbindung mit einer persona einen wiederkehrenden Ertrag geboten haben; anderenfalls wäre das eingesetzte Kapital verloren gewesen. ${ }^{45}$ Die Nutzung des Altarvermögens muß also zwischen der persona und Sint Baafs in irgendeiner Weise mittels einer vertraglichen Regelung geteilt gewesen sein. Nach dem Erwerb des Altarbesitzes war die Abtei in der Lage, die Auswahl der persona zu beeinflussen. Man sieht hier einen Schritt in der Entwicklung des ius patronatus, der in der Herausbildung des ius praesentationis für die Besetzung der personatus von Niederkirchenaltären bestanden hat. ${ }^{46}$

1159 beurkundet Bischof Giraldus von Tournai die Übertragung des personatus, den ein gewisser Godebert in aecclesia de roddenburch besessen habe, an die Abtei Sint Baafs auf Dauer und ohne Einschränkung, vorbehaltlich der gewohnheitsmäßigen Rechte des Ordinarius. ${ }^{47}$

Der personatus der Kirche von Aardenburg befindet sich nunmehr im Besitz der Abtei Sint Baafs. Godebert, sein Veräußerer, den man im 11.Jahrhundert als die persona des Altars bezeichnet hätte, hat mit der Abtei ein Rechtsgeschäft dahingehend abgeschlossen, daß er gegen eine hier nicht genannte Leistung seinen Anteil an der Nutzung des Altarvermögens sowie das Recht zur Delegation der Seelsorgeverpflichtung auf Sint Baafs überträgt. Godebert überträgt seine Rechte durch die Hand des Ordinarius, der auch bei dieser Gelegenheit die bischöflichen Rechte benennt. An dem hier beurkundeten Vertrag sind also drei Parteien beteiligt gewesen: Bischof Giraldus von Tournai, die Abtei Sint Baafs und der Veräußerer des Altars mit Namen Godebert. Von der redemptio ist nicht mehr die Rede; deren simonistischer Charakter ist seit dem Konzil von Clermont 1095 notorisch, weshalb diese Praxis seit dem Ende des 11.Jahrhunderts durch andere, nicht simonieverdächtige Leistungen ersetzt wird. ${ }^{48}$ Die Abtei Sint Baafs ist nunmehr für die

${ }^{45}$ Zur Rentabilität des Kapitals, das während des Hochmittelalters zum Erwerb von Zehntanteilen investiert worden ist, vgl. Van Werveke, Mort-gage, 82, der für das 13. Jahrhundert eine Rendite von $9 \%$ für das derart investierte Kapital ermittelt hat. Van Werveke weist ebd. 63 auch auf den wichtigen Umstand hin, daß sich die Zehnteinkünfte analog der Produktion und damit analog von deren Intensivierung entwickelt haben. Platelle, Le temporel, 152 erläutert an einem Beispiel aus den Jahren 1107-1115, wie rentabel und gleichzeitig beständig gegen Währungsverschlechterungen der Zehntbesitz gewesen ist.

${ }_{46}$ Zur Entwicklung des Patronats vgl. Landau, Ius patronatus, 16-37. Bisweilen haben die Ordinarien den kirchlichen Institutionen sogar das Recht zur Präsentation der persona ausdrücklich zugestanden, vgl. Vleeschouwers, Oorkonden van de Sint-Baafsabdij, Nr. 18, 21. Für die Diözese Cambrai hat Duvosquel, Chartes de donation 151 eine Reihe von Verträgen aus dem 11.Jahrhundert analysiert, in denen die Veräußerer von Altären sich deren Nutzung auf Lebenszeit audrücklich ausbedungen haben: „hac imposita conditione, ut in vita sua illud [sc. altare] tenerent". Zur Übertragung von Eigenkirchen an die Abtei Saint-Victor in Paris zum Zweck der Versorgung nachgeborener Söhne vgl. Schoebel, Archiv, 241.

${ }^{47}$ Ed. Vleeschouwers, Oorkonden van de Sint-Baafsabdij, Nr. 42.

48 Zur erstmaligen Verurteilung der Praxis der redemptio durch Konzilien (Clermont 1095, Nîmes 1096) vgl. Schreiber, Kurie und Kloster 2, 49-50. Jedoch hatte bereits Gregor VII. in seinem Schreiben an Bischof Hugo von Die (betreffend die Wahlangelegenheit Gerhards von Cambrai, die Einberufung eines Konzils in Frankreich sowie andere Sachen) 1077 Mai 12 die redemptio verurteilt (MGH EE sel. II,1 332). Zum Ersatz der redemptio durch Anniversarien 
Ausübung der Seelsorge an der Kirche von Aardenburg verantwortlich und kommt dieser Verpflichtung auf herkömmliche Weise nach, wie im Folgenden deutlich wird.

1169 beurkundet Bischof Walter von Tournai einen Vertrag zwischen den Priestern der Kirche von rodenburg, deren Pfarrbezirk sehr umfangreich und ausgedehnt sei und deren Seelsorgepflicht deshalb verringert werden müsse, einerseits sowie dem Priester der im Pfarrbezirk gelegenen Kapelle Henekingwerue (Hanekenswerve) andererseits. Der Vertrag regelt die Anteile der beiden Parteien an den Oblationen, die an den hohen kirchlichen Festtagen und bei der Vornahme sakramentaler Handlungen in der Kapelle vereinnahmt werden. Zwei Drittel stehen dem Priester der Kapelle und ein Drittel steht den Priestern der Pfarrkirche maior ecclesia - $\mathrm{zu}^{49}$

Die Oblationen sind ein konstitutiver Teil der Einkünfte des Pfarrbenefiziums. Die Priester der Pfarrkirche von Aardenburg verfügen hier frei über diese Einkünfte, denn die Urkunde enthält keine Hinweise auf eine irgendwie geartete Mitwirkung des Abtes oder des Konventes von Sint Baafs. Folglich müssen die Priester die Inhaber des Pfarrbenefiziums von Aardenburg gewesen sein, da sie über einen maßgeblichen Teil von dessen Einkünften vertraglich frei verfügen. ${ }^{50}$

Die Kirche und der personatus von Aardenburg gehörten, wie man der Urkunde von 1159 entnehmen kann, der Abtei Sint Baafs. Über welches Recht verfügte nun die Abtei in Gestalt des personatus?

Die Abtei verfügte nicht über das Pfarrbenefizium in unbeschränktem Maße; über das Pfarrbenefizium bzw. über einen konstitutiven Teil verfügten die Priester der Kirche von Aardenburg. Die Abtei verfügte hingegen über das Präsentationsrecht für das Pfarrbenefizium von Aardenburg. Dies heißt, der Abt von Sint Baafs

oder turnusmäßige Gedächtnismessen vgl. Platelle, Le temporel, 152. Vgl. auch zu einem Beispiel aus der Diözese Tournai Bischof Radbod II. von Noyon-Tournai für Saint-Pierre in Lille 1090 Februar 19, ed. Hautcour, Cartulaire, Nr. 7. Schreiber, Kurie und Kloster, 2, 82 hat vermutet, daß bisweilen wohl das cathedraticum an die Stelle der redemptio getreten sei. Ungeachtet des Verbots der redemptio auf dem Konzil von Clermont 1095 mußte beispielsweise Paschalis II. noch im Jahre 1100 den Bischof Rannulf von Saintes ebenso wie den des Kirchenrechts sicherlich nicht unkundigen Bischof Ivo von Chartres abmahnen: Beide hatten offenbar die Praxis der redemptio faktisch beibehalten und waren dem Konzilsbeschluß nur insoweit nachgekommen, als sie die Benennung für diese Praxis geändert hatten (Migne, PL. 163,36 , JL 5820). Ivo von Chartres war jedoch nicht der einzige, bei dem mangelnde Einheit von Wort (siehe Anm. 26) und Tat festzustellen ist; vgl. zu dem Abt Gottfried von Vendôme Mollat, Restitution des églises, 416-417.

49 Ed. Vleeschouwers, Oorkonden van de Sint-Baafsabdij Nr. 49. Zu Hanekenswerve, heute wüst, seinerzeit gelegen in der Nähe der heutigen Ortschaft Draaibrug (provincie Zeeland, Niederlande), vgl. Verbulst, Sint-Baafsabdij, Karte IX; Topografische kaart van Nederland 1:25000, uitgave 1986, blad 54a; Gottschalk, Historische geografie, 5.

${ }^{50} \mathrm{Zu}$ der nicht zuletzt in der Diözese Tournai während des Hochmittelalters verbreiteten Praxis, daß einer Pfarrkirche mehrere Pfarrpriester gleichzeitig zugeordnet gewesen sind, die feste Anteile am Gesamtertrag des Benefizialvermögens besaßen und zumeist à tour de rôle die Kirche bedienten, vgl. Nicolas Huygbebaert, Notes sur l'origine de la pluralité des curés dans l'ancien comté de Flandre, in: Revue d'histoire ecclésiastique 64 (1969) 403-417. Vgl. auch Lindner, Anstellung der Hilfspriester, 19. 
hat dem Bischof von Tournai zwecks Prüfung der Idoneität und Übertragung der cura animarum die in der Urkunde von 1169 bezeichneten Priester präsentiert. Der Bischof hat die Präsentierten geprüft und ihnen bei gegebener Idoneität die cura animarum übertragen. ${ }^{51}$

\section{Das Institut der persona}

Altare sine persona, altare absque persona, altare impersonaliter possidendum sind Formulierungen, die die Aufhebung des Rechtsinstituts der persona bezeichnen. Die Aufhebung dieses Instituts hat zur Folge, daß nunmehr die kirchliche Institution das Präsentationsrecht für das Pfarrbenefizium des Altars hat, der sich in ihrem Besitz befindet.

Mit der Aufhebung der persona bzw. des personatus wird ein Rechtsinstitut beseitigt, das geschaffen worden war zum Zweck der Nutzung der Altareinkünfte durch eine natürliche Person. Für die Schaffung dieses Instituts war das Bestreben der Bischöfe maßgebend gewesen, nicht nur das Verfügungsrecht über kirchliche Ämter und Güter wiederzuerlangen, sondern auch dieses Recht nach Erlangung mittels der redemptio materiell zu nutzen.

Die redemptio war jedoch nicht der einzige Grund für das Interesse der Bischöfe an dem Institut der persona. Ein weiterer, nicht minder bedeutsamer Grund war die Verpflichtung der persona zur Leistung der turnusmäßigen Abgaben an den Ordinarius. Diese Tatsache erklärt auch, warum nach dem Ersatz der redemptio durch eine einmal vereinbarte, auf Dauer geltende Leistung - Anniversarstiftung oder Aufnahme in die Gebetsgemeinschaft - das Institut der persona nicht aufgehoben wird. Nachdem die Auffassung von der redemptio als simonistischer Handlung sich durchgesetzt hat, ist offenbar allenthalben über diese Einrichtung zwischen den Abteien und Kollegiatkapiteln einerseits und den Ordinarien andererseits verhandelt worden. Die Folge sind Urkunden, in denen vom Ersatz der redemptio, nicht jedoch von der Aufhebung des Instituts der persona die Rede ist. ${ }^{52}$

51 Das Präsentationsrecht der kirchlichen Institutionen in der Diözese Tournai war faktisch ein Kollationsrecht, denn der Ordinarius war bei gegebener Idoneität zur Übertragung der cura animarum verpflichtet, die im übrigen nach der Einweisung in das Benefizium (institutio) erfolgte; vgl. zu einem anschaulichen Beispiel Vleeschouwers, Oorkonden van de SintBaafsabdij, Nr. 84. Zu den Rechtsakten bei der Besetzung eines Benefiziums an einer Eigenkirche mit Pfarreirechten für die Zeit des 12. Jahrhunderts vgl. mit Beispielen aus der kurialen Entscheidungspraxis Schreiber, Kurie und Kloster, 2 54-65.

52 Vgl. beispielsweise die Übertragung des Altars von Saint-Médard de Barisis durch Bischof Bartholomaeus von Laon an die Abtei Saint-Amand 1136 pro salute anime nostre (Platelle, Le temporel 192). Zu einem anschaulichen Beispiel für die Bestätigung des Altarbesitzes sub personatu und die Betonung der Leistungspflicht der personae für die dem Ordinarius und seinen Amtsträgern geschuldeten iura vgl. Bischof Balderich von Noyon-Tournai für die Abtei Sint Baafs 1105: „Concessimus itaque ego scilicet et Lambertus archidiaconus ei eiusque loco eiusque monachis predicta altaria perpetuo sub personatu tenenda ea videlicet conditione, quod personis eorundem altarium morte seu qualicumque modo a personatu illo decedentibus alie ab episcopo seu ab eius ministris pro voluntate abbatis substituantur personae 
Die Bischöfe, wie alle ihre Zeitgenossen zu Beginn des 12.Jahrhunderts noch in personalen Bezügen denkend und in Form von konkreten, rechtssymbolischen Akten handelnd, haben auf der Beibehaltung der persona bestanden; weil diese als natürliche Person die Gewähr für die Zahlung der Abgaben an den Bischof bot. ${ }^{53}$ Aus diesem Grunde kam es zu der eigentümlichen Konstruktion, daß eine

quae et ipsorum altarium curam gerant et synodalia iura episcopo eiusque ministris sicut antea solvant" (Vleeschouwers, Oorkonden van de Sint-Baafsabdij, Nr. 18). Vgl. auch Bischof Lambert von Arras für Saint-Pierre in Lille 1111 (Migne, PL, 162, 713-714): Der obedientiarius, das heißt die persona, erhält nach seiner Nomination durch die Kanoniker von SaintPierre den Altar durch die $\mathrm{H}$ and des Ordinarius absque omni emptione et venalitate gratis und ist diesem für die iura episcopalia sowie für die Präsentation des Seelsorgepriesters verantwortlich. Die beiden letztgenannten Beispiele sind aus bischöflicher Sicht durchaus nicht gleichartig gewesen. Bei den Kollegiatkapiteln war es naheliegende Praxis, daß die Kapitelversammlung einen Kanoniker aus ihren Reihen als persona eines in Besitz gehaltenen Altars nominierte; dieser Kanoniker delegierte dann die Seelsorgeverpflichtung an einen Priester, der seinerseits den Altar bediente. Die Interessen des Ordinarius bleiben bei diesem Verfahren gewahrt: Es gab einen Leistungspflichtigen für die iura episcopalia (Besuch der Diözesansynode und Entrichtung des Cathedraticum sowie des Synodaticum) in Gestalt der persona, während der Seelsorgepriester, der dem Ordinarius präsentiert werden mußte, durch die Pflicht zum Besuch der capitula des Archidiakons und des Landdekans ständig in die Diözesanhierarchie eingebunden war. Anders verhielt es sich, wenn eine Abtei einen Altar besaß. In diesem Fall war das Institut der persona ausgesprochen hinderlich, insoweit der Abt einen seiner Mönche mit entsprechender Weihevoraussetzung den Altar bedienen und auf diese Weise nahezu alle Altarerträge der Abtei zukommen lassen konnte; der betreffende Mönch war schließlich dem Armutsgebot unterworfen und ungeachtet seiner Stellung in der Diözesanhierarchie seinem Abt gegenüber gehorsamspflichtig. Gerade wegen dieses Sachverhalts war es aus bischöflicher Sicht nicht geboten, ein derartiges Verfahren zu dulden und damit über kurz oder lang die Leitungsgewalt des Ordinarius beeinträchtigen zu lassen. Besaß also eine Abtei einen Altar, so war es aus der Sicht des Ordinarius doppelt notwendig, auch nach dem Verzicht auf die redemptio das Institut der persona bestehen zu lassen. Zu einem interessanten Sonderfall schließlich vgl. Bischof Simon von Noyon-Tournai für Sint Pieters in Gent 1140 (Foppens, Miraei opera diplomatica, 2 967-968): Bischof Simon hebt das Institut der persona an 25 namentlich genannten Altären auf unter der Bedingung, daß der Abt von Sint Pieters wie auch jeder seiner Nachfolger die persona sei, die in Zukunft an der Diözesansynode teilnehmen und jährlich die iura pontificalia zahlen werde.

53 Zur konstitutiven Bedeutung symbolischer Akte für mittelalterliche Rechtsgeschäfte vgl. H.-J. Becker, Artikel ,Rechtsritual', in: Handwörterbuch zur deutschen Rechtsgeschichte 4 (Berlin 1990) 337-339; vgl. auch etwas allgemeiner Adalbert Erler, Artikel ,Rechtssymbolik, Rechtssymbole', in: ebd., 381-383. Ein aufschlußreiches Beispiel aus dem Jahr 1064 für das bischöfliche Interesse an natürlichen Personen, die für die Erfüllung der dem Ordinarius geschuldeten Leistungen haften, bietet Ludwig Falkenstein, Alexander III. und die Abtei Corbie. Ein Beitrag zum Gewohnheitsrecht exemter Kirchen im 12.Jahrhundert, in: Archivum Historiae Pontificiae 27 (1989) 85-195, ebd. 105-110, insbesondere Anm. 92: Der Ordinarius besteht auf der Benennung nicht nur eines, sondern zweier Kleriker, die im Hinblick auf einen Altar für den Besuch der Diözesansynode und für die Sendgerichtsabgaben verantwortlich sind. Bemerkenswert ist in diesem Zusammenhang auch, daß noch die klassische Kanonistik in der Phase der Herausbildung des Patronatsrechts „zunächst juristischen Personen die Fähigkeit bestritten (hat), das Patronat originär zu erwerben“, vgl. Landau, Ius patronatus, 41-42. Bei den Abteien verbleibt nach der Aufhebung des Instituts der persona häufig ein sogenannter obedientiarius monachus als der dem Ordinarius gegenüber Verantwort- 
juristische Person - Abtei, Kollegiatkapitel - einen Altar besaß, dessen Nutzung sie jeweils mit einer natürlichen Person - persona - teilen mußte. Für die Bischöfe wurde das Institut der persona zu dem Zeitpunkt obsolet, als ihre Interessen durch neue, bislang offenbar nicht vorstellbare Lösungen gewahrt werden konnten. Eine dieser neuen Lösungen bestand darin, daß zum einen die Leiter der altarbesitzenden kirchlichen Institutionen sich zum Besuch der Diözesansynode und damit in eindeutiger Weise zur Obödienz auch im Hinblick auf den Altar verpflichteten, während zum anderen die Seelsorgepriester die Leistungspflichtigen für die turnusmäßigen Abgaben wurden. ${ }^{54}$

Für die kirchlichen Institutionen, die das Benefizialvermögen ihrer Niederkirchen möglichst unbeschränkt nutzen wollten, war das Rechtsinstitut der persona ein Hindernis. Diese Institutionen traten nämlich mit ihren Interessen an der Nutzung der lukrativen Altareinkünfte zu einem Zeitpunkt auf den Plan, zu dem bereits natürliche Personen in Gestalt der personae diese Einkünfte vereinnahmten. Die Trennung von altare und ecclesia war bereits durchgeführt, eine persona war Inhaberin des jeweiligen altare respektive des jeweiligen Benefizialvermögens, die persona schließlich nutzte die Erträge dieses Vermögens, indem sie den am Altar tätigen Seelsorgepriester mit einem möglichst geringen Anteil an den Erträgen entlohnte. Den Abteien und Kollegiatkapiteln war es demnach nicht möglich, auf die Nutzung des Benefizialvermögens unmittelbar Einfluß zu nehmen. Die Lage, in der sich die kirchlichen Institutionen befanden, kann man auf folgende Weise umschreiben: Die Abtei oder das Kollegiatkapitel verfügte über das Obereigentum an dem Altar, während die persona das Nutzeigentum innehatte; aufgrund dieses Rechtsverhältnisses erhielt die Obereigentümerin ein Fixum als

liche für den jeweiligen Altar, vgl. die Einleitung zum Druck der Konzilskanones von Reims 1049, in: Recueil des historiens des Gaules et de la France 11 (Paris $\left.{ }^{2} 1876\right) 521$.

54 Vgl. Bischof Simon von Noyon-Tournai für Sint Pieters in Gent 1140 (wie Anm. 52): Der Abt ist verpflichtet zur Teilnahme an der Diözesansynode und zur Leistung der iura episcopalia, die Seelsorgepriester hingegen sind verpflichtet zur Teilnahme an den capitula des Archidiakons und des Landdekans. Zu den Pflichten der presbyteri, die der Leiter einer kirchlichen Institution an einem Altar eingesetzt hat, sowie zu einer Erläuterung der episcopalia et synodalia iura vgl. Bischof Odo von Cambrai für Saint-Martin de Tournai 1105 (ed. d'Herbomez, Chartes de Saint-Martin 1 Nr. 9). Die päpstliche Kurie respektierte die Leistungspflicht für die Abgaben, indem sie eine entsprechende Klausel in die Privilegien einfügte, die die kirchlichen Institutionen für ihren Altarbesitz impetrierten, vgl. zum Beispiel Calixt II. für Saint-Amand d'Elnon 1119 November 20, Migne (PL. 163, 1139-1141, JL 6784): „Porro altaria, quae in diversis parochiis possessione legitima possidetis, ab omni personatu libera vobis vestrisque successoribus in perpetuum servanda censemus, salvis nimirum consuetis episcoporum vel episcopalium ministrorum obsoniis." - Zur Existenz des Instituts der persona noch gegen Ende des 12. Jahrhunderts vgl. das Konzil von Rouen 1190 can. 8 (Mansi 22 583B). Vgl. auch zur Verpflichtung einer persona um das Jahr 1225, die Kirche von einem. capellanus bedienen zu lassen: Cartulaire du prieuré de Saint-Hippolyte de Vivoin et de ses annexes, ed. L. J. Denis (Paris-Ligugé 1894) 12 Nr. 18. Vgl. des weiteren can. 17 der Precepta synodalia des Bischofs von Cambrai Roger de Wavrin vom Ende des 12. Jahrhunderts mit der Aufforderung an die personae, die altarbedienenden presbyteri dem Ordinarius zwecks Übertragung der cura animarum zu präsentieren, vgl. die Edition von Joseph Avril, Les precepta synodalia de Roger de Cambrai, in: Bulletin of Medieval Canon Law 2 (1972) 11. 
eine Art Rekognitionszins, während die persona die Erträge unbeschränkt nutzen konnte, da sie - wegen der zahlreichen Bewerber um eine Seelsorgestelle - den altarbedienenden Priester mit einem geringen Anteil abfinden konnte.

Wie bereits ausgeführt, erwarben die kirchlichen Institutionen seit der Jahrtausendwende zunehmend Altäre von Niederkirchen. Sie erwarben diese Altäre zu den Altären und Niederkirchen hinzu, die sie bereits seit längerem besaßen. Zählte der Altar einer Pfarrkirche bereits zum eigenen Vermögen, wie dies bei dem Altar von Aardenburg der Fall war, so bestand der Ertrag in einer periodisch wiederkehrenden, aber in der Höhe begrenzten Abgabe. Erwarb eine kirchliche Institution ein altare cum persona durch Rechtsgeschäft mit bischöflicher Beteiligung, so war die Folge dieselbe; der Summe oder Leistung, die man für den Altar gegeben hatte, stand ein periodisch wiederkehrender, jedoch begrenzter Ertrag gegenüber. Die Stellung der persona war in diesem Rechtsverhältnis die stärkere, weil die persona Inhaberin des Benefiziums war und in dieser Eigenschaft unmittelbar mit dem Seelsorgepriester verhandelte; dieser war nämlich der Bewirtschafter des Benefizialvermögens vor Ort, und mit diesem mußte die Nutzung vertraglich geregelt werden. Es war also die persona, die unter den Bewerbern um eine Seelsorgestelle denjenigen auswählen konnte, der die für sie günstigsten Vertragsbedingungen akzeptierte.

Sobald das Institut der persona durch bischöfliches Privileg aufgehoben wurde, änderte sich die Rechtsstellung der kirchlichen Institution grundlegend. In den Urkunden nämlich, die die Aufhebung des Instituts der persona bezeugen, ist regelmäßig das nunmehr gegebene Recht der altarbesitzenden Institution aufgeführt, dem Ordinarius in Zukunft den presbyter oder die presbyteri zu benennen. Bei diesem presbyter beziehungsweise bei diesen presbyteri handelte es sich, wie das Beispiel des Altars von Aardenburg gezeigt hat, um die ordentlichen Inhaber des Pfarrbenefiziums; diesen mußte der Bischof bei gegebener Idoneität das Benefizium sowie die cura animarum übertragen. Die kirchliche Institution rückte damit insoweit in die Stellung der vormaligen persona ein, als zukünftig sie berechtigt war, unmittelbar mit den Bewerbern um ein Pfarrbenefizium zu verhandeln und schließlich denjenigen auszuwählen, der die höchste jährliche Pachtsumme bot. Mit anderen Worten: Die Aufhebung des Instituts der persona führte zu dem ius praesentationis der Abteien und Kollegiatkapitel für die Pfarrbenefizien ihrer Altäre und Kirchen; an die Stelle der Möglichkeit, die Entscheidung des Bischofs bei der Vergabe eines altare zugunsten einer gewünschten persona zu beeinflussen, trat das Recht zur Benennung eines zukünftigen Benefiziaten. ${ }^{55}$

55 Das Rechtsverhältnis im Übergang vom Institut der Eigenkirche zum Patronat beschreibt als Obereigentum der kirchlichen Institution bei gleichzeitiger voller Nutzung durch den Benefizieninhaber Nikolaus Hilling, Neueste Forschungen über die Inkorporation von Kirchen, in: Archiv für katholisches Kirchenrecht 121 (1941) 221-227, ebd. 222. Zum ius conductus als Recht der kirchlichen Institution auf feste jährliche Zinszahlungen des Benefizieninhabers vgl. Schreiber, Kurie und Kloster 2, 68, 84-85. Zum Versuch der Zinserhöhung nach Vertragsabschluß zwischen dem Leiter der kirchlichen Institution und dem Benefizieninhaber vgl. das Mandat Alexanders III. an Erzbischof Heinrich von Reims (Migne, PL, 200, 791, 
Die Unterscheidung zwischen altare und ecclesia, zwischen altare und persona, der Ersatz der persona als natürlicher Person durch das ius praesentationis der juristischen Person waren kirchenpolitisch und wirtschaftlich motiviert. Gleichzeitig standen diese Entwicklungen notwendigerweise in einem rechts- und bildungsgeschichtlichen Zusammenhang. In dem Prozeß, der zur Ablösung des Instituts der Eigenkirche durch das Patronatsrecht führte, erscheint als kurzlebiges Institut des Überganges - im wesentlichen von der Mitte des 11. bis zum Beginn des 12. Jahrhunderts - die persona. Die persona war die Nachfolgerin des Eigenkirchenherrn, was die Nutzung der Spiritualien betrifft, und die Vorläuferin der Rechtsinstitute, die sich auf das beneficium ecclesiasticum an Niederkirchen beziehen: Patronat und Inkorporation.

Auch zwischen der beschriebenen Rechtsentwicklung und der Rezeption antiker Gelehrsamkeit bestand ein Zusammenhang. Der Zusammenhang war zum einen personaler Art. Führende Förderer des Studiums der Dialektik wie überhaupt der Artesstudien bekleideten im Verlauf ihrer Karriere hochrangige Kirchenämter; in diesen Funktionen waren sie in die kirchliche Rechtswirklichkeit eingebunden und Partei bei Rechtsgeschäften. Verwiesen sei hier beispielhaft auf Abt Abbo von Fleury und Bischof Ivo von Chartres. Der Zusammenhang war zum zweiten entwicklungsmäßiger Art. Rezeption, Überlieferung und gesellschaftliche Wirkung antiker Gelehrsamkeit verliefen vom 9. bis zum 12.Jahrhundert gewissermaßen im Gleichschritt mit der sich differenzierenden kirchlichen Rechtswirklichkeit. Das Herrschaftsrecht über die Eigenkirche wurde differenziert in Nutzungs- und Beteiligungsrechte hinsichtlich des Altars und des Kirchengebäudes; zwecks Nutzung des Altars, das heißt der Spiritualien, wurde das Institut der persona gebildet. Fortschreitende, einander bedingende Bildungs- und Rechtsentwicklungen führten schließlich zur Aufhebung des Instituts der persona, das nicht mehr benötigt wurde. An seiner Statt entwickelte die kanonistische Wissenschaft die genannten, erheblich langlebigeren und erheblich weiter verbreiteten Rechtsinstitute: Patronat und Inkorporation.

JL 12005). Das Problem der Zinserhöhung war offenbar kein unbedeutendes, denn es ist mehrfach an der päpstlichen Kurie behandelt worden; entsprechende Regelungen sind in das Dekretalenrecht eingegangen, vgl. Alexander III. JL 13842 (X 3.39.9), Lucius III. JL 14964 (X 3.39.13), Clemens III. JL 16600 (X 3.39.15). Zu den Verträgen zwischen Kirchenbesitzern und deren Priestern hinsichtlich der Teilung der Einkünfte vgl. Scbreiber, Gregor VII., 152. Der materielle Aspekt des Instituts der persona aus der Sicht der kirchlichen Institutionen geht hervor aus der Formulierung, „altaria, diversis olim exactionibus et personis adgravata, liberrima traditione absque personatu concessi, " in der Urkunde des Bischofs Balderich von Noyon-Tournai für die Abtei Saint-Quentin-en-l'Ile 1110, in der dieser der Besitz aller ihrer Altäre in den Diözesen Noyon und Tournai bestätigt werden, vgl. Duvivier, Actes et documents, 322-329. 


\begin{abstract}
ANHANG:
URKUNDEN BETREFFEND DEN ALTAR VON AARDENBURG 1096, 1159,1169

Bischof Radbod von Noyon-Tournai beurkundet auf Bitten des Abtes Adelard von Sint Baafs in Gent dieser Abtei die Befreiung des Altars von Aardenburg sowie der von diesem abhängigen Kapellen auf der Insel Wulpen von Abgaben an den Ordinarius, insbesondere bei Schenkungen von Dritten an den Altar, mit Auflagen betreffend die Teilnahme an der Diözesansynode, die Zahlung der $r e-$ demptio und des Cathedraticum sowie die Entrichtung der Procuratio anläßlich der Sendgerichtstermine des Archidiakons.
\end{abstract}

\title{
Tournai, 1096 September 14 \\ [Gysseling-Koch, Diplomata belgica, I Nr. 143]
}

IN NOMINE SANCTAE ET INDIVIDVAE TRINITATIS; Patris et Filii et Spiritus Sancti. Radbodus Dei gratia Nouiomensium seu Tornacensium episcopus, omnibus fidelibus tam futuris quam presentibus. Sinum sanctae matris aecclesiae dilatare, sicque salutem animarum aedificare, apostolica sententia, quia dicit: "dum tempus habemus operemur bonum ad omnes, maxime ad domesticos fidei“, commoniti ab archidiacono Lantberto necnon a caeteris sani consilii clericis, consilium accepimus, quasdam aecclesias ad congregationes monachorum siue clericorum pertinentes, libertate donare, quatinus ad illam libertatem nobis pararetur aditus, qua nos liberauit Dominus Iesus. Precibus igitur cari filii nostri Adelardi, qui est abbas aecclesiae sancti Bauonis, benigne condescentes, altari de Roddenburg, cum capellis quae sunt in insula nomine Wlpa, et cum omnibus appenditiis, ius libertatits concedimus, concessumque pontificali auctoritate contra omnem exactionem confirmamus; sub hac tamen conditione, ut persona curam synodi prosequatur, et in festiuitate apostolorum Simonis et Iudae decem solidi, totidemque in mutatione personae persoluantur, quarto etiam anno archidiacono infra parroechiam illam synodalia iura exercenti, consueta amministretur impensa. Vt autem huius libertatis concessio immutabilis permaneat, sigilli inpressione signamus, ac caeteris signandam tradimus.

S. domni Radbodi episcopi. S. Lantberti archidiaconi. S. Petri decani. S. Herimanni prepositi. S. Sicheri fratris eius. S. Lietberti. S. Tietberti. S. Rainberti. S. Desiderii, S. Bernardi. S. Eustachii. S. Dodini decani. S. Bertulfi. S. Raineri. S. Tancradi. S. Ingranni decani. S. Frederici decani.

Actum Tornaci, VIIIuo decimo kalendas octobris, anno dominicae incarnationis M XC VI, indictione IIII, regnante Philippo anno XXXVIII, domno Radbodo episcopante anno XXVIIII.

Ego Wido cancellarius dictaui, relegi ac firmaui.

Bischof Giraldus von Tournai beurkundet die Übertragung des personatus der Kirche von Aardenburg, den bislang ein gewisser Godebert besessen hatte, an die 
Abtei Sint Baafs auf Dauer und ohne Einschränkung, vorbehaltlich der gewohnheitsmäßigen Rechte des Ordinarius.

Tournai, 1159 Juni 30

[Vleeschouwers, Oorkonden van de Sint-Baafsabdij, Nr. 42]

IN NOMINE PATRIS ET FILII ET SPIRITUS SANCTI AMEN. Ego Giraldus, Dei gratia Tornacensium episcopus, reverendo abbati aecclesiae Sancti Bauonis Bettoni ceterisque fratribus tam presentibus quam futuris in perpetuum. Debemus iuxta apostolum operari bonum ad omnes, maxime autem ad domesticos fidei. Quicquid divino cultui locis mancipatis ad suggestionem virorum fidelium divina inspiratione conferimus, id nobis profuturum ad aeternae remunerationis premia capessenda confidimus. Quamobrem personatum, quem in aecclesia de Roddenburch Godebertus tenuerat, aecclesiae Sancti Bauonis perpetuo tenendum libere et absolute, religiosarum personarum peticioni et consilio adquiescentes, contradidimus salvo iure episcopali in omnibus. Sicut ea quae predecessorum nostrorum temporibus aecclesiis intuitu misericordiae et pietatis collata sunt, firma et inconvulsa in posterum permanere cupimus, nichilomonus ea, quae nos annuente Domino ob salutem animae nostrae et predecessorum nostrorum viris Deo militantibus devotissime contulimus, ut non divellantur sive imminuantur pontificali providendum sollicitudine censemus.

Hoc vero donum nostrum, ut ratum et firmum permaneat, sigilli nostri impressione confirmavimus et personis quae interfuerunt subnotatis corroboravimus. Signum domni Giraldi Tornacensis episcopi. S. Galteri decani. S. Euerardi, Desiderii archydiaconorum. S. Letberti prepositi. S. Letberti cancellarii et cantoris. S. Gotsuini, Symonis presbiterorum. S. Hugonis abbatis Sancti Amandi. S. Galteri abbatis Sancti Martini. S. Sigeri abbatis Sancti Petri. S. Anselmi abbatis Cisoniensis. S. Raineri diaconi. S. Herbrandi. S. Lamberti. S. Guiberti. S. Oliueri, Gotsuini, Danielis.

Actum Tornachi, II Kalendas Julii anno incarnationis dominicae $\mathrm{M}^{\circ} \mathrm{CLVIIII}^{\circ}$. Bischof Walter von Tournai beurkundet einen Vertrag zwischen den Priestern der Kirche von Aardenburg einerseits sowie dem Priester der im Pfarrbezirk gelegenen Kapelle Hanekenswerve andererseits betreffend die Anteile der beiden Parteien an den Oblationen, die an den hohen kirchlichen Festtagen und bei der Vornahme sakramentaler Handlungen in der Kapelle vereinnahmt werden.

Tournai [1168 Dezember 25 - 1169 Dezember 24] 1169

[Vleeschouwers, Oorkonden van de Sint-Baafsabdij, Nr. 49]

IN NOMINE PATRIS ET FILII ET SPIRITUS SANCTI AMEN. Ego Galterus, Dei gratia Tornacensis episcopus, tam futuris quam presentibus in perpetuum. Notum sit omnibus Sanctae Matris Ecclesiae filiis quod presbiteri maioris aecclesiae de Rodenburc, cum eorum parrochia nimis ampla et diffusa esse videretur, ad vitandum laborem proprium et tollendum hominum nascentium atque morien- 
tium periculum, cum presbitero capelle de Henekingwerue in presentia clericorum nostrorum eo pacto convenerunt ut eis ille in officio sacerdotali subveniret et quinquies in anno, videlicet in die Natalis Domini, in die Pasche, in die Pentecostes, in festivitate Omnium Sanctorum, in die Animarum, insuper in obsequiis defunctorum super terram presentium, in caelebratione nuptiarum, in purificatione mulierum, in baptismo parvulorum duas partes oblationum capellae suae optineret et terciam partem presbiteris maioris aecclesiae reconsignaret. Si quis etiam de parrochianis in maiori aecclesia locum sepulturae sibi eligeret, sepulturam ei contradicere presbitero de capella non liceret.

Haec omnia, salvo iure abbatis qui personatum optinet, inter eos stabilita sunt et testimonio eorum qui interfuerunt et sigilli nostri impressione roborata. Signum Ledberti decani. S. Euerardi archidiaconi. S. Desiderii archidiaconi. S. Roberti prepositi de Herlebecca. S. Ledberti cancellarii. S. magistri Symonis. S. Thome de Sal[inis]. S. Magistri Walteri. S. magistri Gozuini. S. magistri Lamberti. Actum apud Tornacum, anno incarnationis Domini $\mathrm{M}^{\circ} \mathrm{C}^{\circ} \mathrm{LX}^{\circ} \mathrm{IX}^{\circ}$. 